\title{
Ecos, influencias e manifestacións da Escola Nova e Activa en Galicia
}

\author{
(Echoes, influences and manifestations of the New Active School in \\ Galicia)
}

\author{
Antón COSTA RICO \\ Universidade de Santiago
}

RESUM0: Ata onde chegou a impregnación do movemento internacional da Escola Nova e Activa en Galiza ao longo das primeiras décadas do século XX? Esta é a cuestión que pretendemos responder e desenvolver, para o que previamente estabelecemos necesarias precisións conceptuais e históricas que nos faciliten a comprensión de que, alén da presenza de prácticas educativas que responden plenamente a este ideario, houbo neste período accións, reflexións e prácticas pedagóxicas que desde 0 activismo metodolóxico, desde o positivismo e, en ocasións, desde o rexeneracionismo escolar foron converxentes e/ou prepararon 0 terreo para tal impregnación. 0 impulso que agromaba con algunha forza sociolóxica foi coutado pola ditadura política en 1936.

PALABRAS CLAVE: Escola Nova e Activa; Galicia; profesorado; activismo didáctico; europeización

ABSTRACT: How far did the impregnation of the international movement of the New and Active School in Galicia reach during the first decades of the 20th century? This is the question that we pretend to answer and develop, for what we previously establish necessary conceptual and historical clarifications that facilitate the understanding that further of the presence of educative practices that answer fully to this vision, there was in this period actions, reflections and pedagogical practices that, from the methodological activism, from the positivism and, in occasions, from the School Regenerationism converged and/or paved the way for such impregnation. The impulse that expanded with some sociological strength was cut by the political dictatorship in 1936 .

KEYWORDS: New Active School; Galicia; teachers; didactic activism; Europeanisation 
Para Antía Cal, Tatá Viñas e Palmira González Boullosa (in memoriam); tamén para Xosé Lastra, Mariló Candedo e Paco Veiga. Todas e todos deron vida nova e trouxeron ata hoxe a utopía da Educación Nova. ${ }^{1}$

\section{Entrando na cuestión}

Ata onde chegou a impregnación escolanovista na Galiza ao longo das primeiras décadas do século XX? Esta é a cuestión que pretendemos responder e desenvolver neste texto, ${ }^{2}$ con aquelas oportunas precisións que nos faciliten a comprensión de que, máis alá da presenza de prácticas educativas que responden plenamente a este ideario, houbo neste período accións, reflexións e prácticas pedagóxicas que desde 0 activismo metodolóxico foron converxentes e/ou prepararon o terreo para aquelas.

Neste sentido, non debemos confundir as mostras tipificadas como «activisimo didáctico ou pedagóxico», visíbeis desde finais do século XIX, coa resonancia certa do que coñecemos como movemento internacional da Escola Nova e Activa, existente naquel período ata o punto de ocasionar unha "revolución copernicana" na educación, tal como escribiu un dos seus líderes, Édouard Claparède (1873-1940). Esta revolución copernicana foi un fenómeno relativamente minoritario entre as manifestacións escolares, se 0 examinamos na plenitude dos seus significados.

Porén, de modo similar a como a historiografía educativa fala da "Institución difusa", para referirse ás múltiples expresións da influencia difusa e gradual da ILE ${ }^{3}$ ao longo

\footnotetext{
${ }^{1}$ Antía Cal Vázquez, que foi alumna no colexio do Centro Galego da Habana e vai pronto para cen anos, abriu 0 colexio Rosalía de Castro nos pasados anos sesenta; a pedagoga Tatá Viñas, filla do inspector e galeguista Viñas Cortegoso, impulsou pouco despois o colexio Martín Codax, e Palmira González Boullosa puxo a andar o colexio Andersen. Sempre en Vigo e en tempos da ditadura. Tres mulleres educadoras, practicantes da educación nova e activa, laica e aberta á galeguización. Pola súa parte, desde os pasados anos oitenta, en tempo democrático, Xosé Lastra Muruais, Mariló Candedo Gunturiz e Paco Veiga García viñeron sendo corazón e intelixencia da Nova Escola Galega.

Polos primeiros meses de 1974 o vello galeguista Ramón Piñeiro poñía nas miñas mans de inquedo estudante de Pedagoxía unha copia do "Plan pra galeguizazón d'as escolas", que Vicente Risco escribira e publicara en Nós en 1921. 0 documento, do que eu nunca oíra falar, ía dedicado a Ignacio Ares de Parga; daquela, aquel nome non me dicía nada, mais puido a curiosidade para indagar por el e chegar a saber que fora un destacadísimo pedagogo galego, de matriz institucionista, con desempeño relevante en Bos Aires, acción entre os emigrantes galegos e certa influencia en Galicia, que hoxe coñecemos ben. Coa mesma esperanza e desexo de que haxa novas/os educadoras/es con curiosidade polos seus nomes que aquí deixo, para que igualmente se saiba deles.

${ }^{2}$ Son reducidas as achegas previas realizadas a estas cuestións. De salientar polo carácter panorámico: Antón Costa, "Escola Nova e proxecto pedagóxico galego", en Antón Costa, Escolas e Mestres. A educación en Galicia: da Restauración á II República (Santiago de Compostela: Xunta e Galicia, 1989), 305-358; Antón Costa, A reforma da educación en Galicia (1907-1936) (Sada: Ediciós do Castro, 1996).

${ }^{3}$ A Institución Libre de Enseñanza (ILE), liderada desde 1876 polo profesor Francisco Giner de los Ríos, foi, ademais de centro educativo en Madrid, plataforma de pensamento, de creación libre e fonte de impulsos para a renovación da vida educativa e social española, cunha grande influencia na transformación das mentalidades e das prácticas políticas, que contribuirían ao fortalecemento das posicións liberal-democráticas e progresistas. Ten sido motivo de coidadas investigacións. Desde Galicia destacamos: Ángel S. Porto Ucha, La Institución Libre de Enseñanza en Galicia (Sada: Ediciós do Castro, 1986).
} 
da xeografía escolar e cultural hispana, podemos falar in extenso, se ben con algunha cautela, dos "ecos, influencias e manifestacións" que en Galiza se puideron apreciar en relación coa Escola Nova e Activa entre os finais do XIX e o 1936, ${ }^{4}$ un período que non pertence por enteiro e só ao territorio dos estudos históricos, dado que persisten ecos biográficos daquilo. ${ }^{5}$

Cómpre, igualmente, considerar que á beira do que supuxo este movemento da Escola Nova e Activa e, nalgunha medida, preparando o seu terreo, o século XIX rexistrou algunhas novas perspectivas sobre a visión da educación escolar. Cabe, así, destacar a influencia da metodoloxía intuitiva pestalozziana, das orientacións para a educación infantil a partir de Fröebel ou de Madame Pape-Carpentier, do acento psicoloxizante que introducira Herbart e dos avances rexistrados na planificación didáctica da man dos alemáns e herbartianos Karl W. Stoy, Tuiskon Ziller e Frederik Paulsen. E non debemos descoñecer o que supuxeron para a educación o positivismo científico, o evolucionismo - tanto na súa vertente biolóxica e darwiniana, como na súa outra vertente social e spenceriana-, a perspectiva médica e hixienista ou algunhas orientacións filosóficas, como a anarco-socialista (coa súa reivindicación da educación politécnica), a vitalista, a neoidealista e a pragmatista.

Así as cousas, non deberemos asignar un dado modelo escolar (como imaxe simplificada) a unha determinada época ou tempo (adecuadamente delimitado), pois habitualmente coexisten varios modelos nun determinado tempo. Foi isto o que nos levou a titular un recente texto noso como "As varias paisaxes da escola en Galicia" 6 ao referirnos á mesma época da que aquí falaremos: a paisaxe da "escola tradicional", a "paisaxe rexeneracionista da escola nacional española", a "paisaxe da Escola Nova" e a " da escola nova e galega". Agora centraremos a nosa atención na "paisaxe da Escola Nova e Activa" en Galicia, con algunha mención ao escenario previo que podemos cualificar como

\footnotetext{
${ }^{4}$ En 1936 un golpe militar (iniciado 018 de xullo), con alto compoñente fascista, derrubaría 0 constitucional goberno español da II ${ }^{\mathrm{a}}$ República, por medio dunha guerra civil de case tres anos de duración. Neste período e aínda logo desencadearon os golpistas unha brutal e cruenta represión política, ao tempo de promover unha identidade política nacionalista española que refugaba e castigaba as numerosas influencias liberaldemocráticas e progresistas que ata daquela se viñan sentindo no conxunto da vida española e tamén en Galicia, 0 que levou á desaparición física de docentes, ao apagamento de múltiples manifestacións e ao exilio noutros moitos casos.

${ }^{5}$ Como exemplo disto, no outono de 2019 tiven ocasión de rescatar a figura de Apolinar Torres López, un escolanovista vigués, inmolado en 1936, mediante 0 texto Antón Costa. "Modernidade pedagóxica e reivindicación da Escola Nova na prensa da cidade de Vigo (1926-1929): a figura do profesor Apolinar Torres López (1894-1936)," Glaucopis. Instituto de Estudios Vigueses, 24 (2019): 253-292. 0 texto suscitou unha natural curiosidade e satisfacción e foi ocasión en dous casos, desconectados entre si, de comentarios similares expresados en conversa particular por parte de dous intelectuais, situados ambos na década dos setenta anos de vida, e ambos son fillos de mestres que exerceran na República (falamos de Miguel Barros Puente e de Francisco Domínguez, director da Biblioteca Penzol): "na biblioteca familiar, entre outros libros de Pedagoxía, conservamos o Diccionario de Pedagogía de Sánchez Sarto". Deberán saber os lectores e lectoras que este voluminoso dicionario de dous tomos e apertada tipografía, editado en Barcelona en 1936 pola Casa Labor, foi un notábel medio de difusión das perspectivas didácticas e pedagóxicas da Escola Nova e Activa.

${ }^{6}$ Antón Costa, "As varias paisaxes da escola en Galicia", en Castelao Maxistral, ed. Miguel Anxo Seixas Seoane (Santiago de Compostela: Xunta de Galicia, 2018), 64-103.
} 
rexeneracionista, en parte alimentado polo positivismo e a preocupación pola chamada "pedagoxía científica."

\section{Cambios no canon pedagóxico}

\section{Abandonando a "pedagoxía perennis" e adoptando os criterios da "pedagoxía científica"}

A chamada pedagoxía perennis, con claves filosóficas metafísicas e aristotélico-tomistas, sufriu no século XIX convincentes derrotas. 0 positivismo científico alimentaba de xeito crecente a mentalidade de destacados profesores e desde este positivismo Darwin, Ernst Haeckel e Spencer, cada un pola súa parte, viñan asentar as perspectivas evolucionistas. A bioloxía, a fisioloxía e a socioloxía cobraban una destacada relevancia. Desde a bioloxía e a fisioloxía abríanse novos horizontes á psicoloxía na perspectiva da psicoloxía experimental e aos estudos sobre a natureza infantil. Sinalara Rousseau no seu Emilio a necesidade de que os educadores estudasen a natureza infantil para adaptar as súas intervencións e iso era o que se comezaba a facer no XIX, mesmo aínda que os criterios de indagación non eran todos acertados. ${ }^{7}$

E así, Alexander Bain publicaba en 1879 Education as a science, ${ }^{8}$ unha obra que iría ter notábel influencia e na que sistematizaba a educación científico-positivista e psicolóxica, segundo a doutrina asociacionista do empirismo inglés. Estaba a formularse, pois, unha "pedagoxía científica" que se expresou con tres direccións fundamentais: nun caso concedéndolle a máxima relevancia aos factores físico-biolóxicos (dirección biolóxica), noutro á realidade psíquica dos educandos (dirección psicolóxica) e noutro, aos factores humanos (a dirección sociolóxica que abriu Durkheim).

Mark Baldwin publicaba en 1889 os seus Elementos de Psicoloxía ${ }^{9}$ onde facía a distinción entre os feitos psicolóxicos e os exclusivamente fisiolóxicos, e indicaba que os feitos mentais, a diferenza dos físicos, non podían medirse directamente, dada a súa natureza subxectiva, co que abría paso a dúas ciencias distintas, por máis que unidas pola bioloxía. Comezaban os estudos sobre a natureza infantil. ${ }^{10}$ En debate estaban daquela 0

\footnotetext{
${ }^{7}$ Sostivo Dante Morando que, a pesar dos seus méritos: "en general, la dirección científico-experimental dio lugar a investigaciones de dudoso valor, en el campo de la medida de las reacciones fisiológicas del organismo humano y en el de (sus) manifestaciones exteriores, determinadas por la intensidad y desarrollo de sus modificaciones psíquicas [debido a que] la visión puramente 'científica' tiende a identificar el sujeto educado y su conciencia con el resultado de los distintos procesos asociativos y mecánicos de hechos psíquicos determinados por hechos fisiológicos, físicos, sociales o psicológicos antecedentes". Vid. Dante Morando, Pedagogía (Barcelona: Luís Miracle, 1953), 223-224.

${ }^{8}$ En castelán, A. Bain, La ciencia de la educación (Valencia: Terraz, Aliena y Cía. Editores, 1882). (“Traducida al castellano por la Sociedad de profesores titulada Biblioteca Profesional de Educación")

${ }^{9}$ Mark Baldwin, Elementos de Psicología (Madrid: La España Moderna, 1893), 11-14 (Tradución de Edmundo González Blanco)

${ }^{10}$ Recordemos o texto de Darwin, “A Biographical Sketch of an Infant" (1877), o texto de Preyer, Die seele des kindes (1882) ou os estudos de J. Sully e de Bernard Pérez, entre eles L'art et la poesie chez l'enfant (1888), que presenta a natureza infantil como un trazo de unión entre a herdanza biolóxica e a adaptación intelixente (o neno: herdeiro e inventor) ata chegar ás investigacións de Stanley Hall desde EUA, cunha clara afirmación da
} 
concepto preformista (e creacionista) vs. o concepto evolucionista do desenvolvemento, así como a lei bioxenética ou teoría da recapitulación, que na perspectiva spenceriana ${ }^{11}$ afirmaba que 0 desenvolvemento individual resume 0 desenvolvemento humano xeral, como un pasado acumulativo -e isto é moi importante - aberto a un futuro de desenvolvemento indeterminado, orientación esta que irá ter consecuencias no campo das visións da educación.

Un reflexo desta preocupación anovadora, que tenta incorporar achegas procedentes das construcións e debates da chamada pedagoxía científica, podemos atopalo nos textos do pedagogo español Pedro Alcántara García, entre eles a súa Teoría y práctica de la educación y la enseñanza. Curso completo y enciclopédico de Pedagogía, de quen seleccionamos aquí o seu tomo VI: La educación intelectual y los métodos de enseñanza ${ }^{12}$, editado por vez primeira en 1886, e Educación intuitiva y lecciones de cosas $^{13}$ (1881). Salientaba Alcántara a importancia educativa de "utilizar la actividad natural y propia del educando", a necesidade de "respetar la libertad de iniciativa del niño" e de que o traballo escolar fose "atractivo y agradable", manifestándose coñecedor de Buisson, Spencer, Bernard Pérez, Pape-Carpentier, Rousseau, Bain, Marion, Eliseo Reclus, ou do Manuel de Kalkins, entre outras referencias.

Todo 0 tomo $\mathrm{VI}^{14}$ alude deseguida ao espectáculo da natureza como motivo de educación, aos numerosos exercicios intuitivos e ás leccións de cousas, aos xogos infantís e 0 seu emprego didáctico, ao debuxo e aos traballos manuais, ás leccións de cousas, ás coleccións de láminas e de obxectos, aos museos escolares, á música e ao canto, ás exposicións e paseos, á construción e modelaxe de corpos xeométricos, ao levantamento de planos e a diversos medios auxiliares para a aprendizaxe das ciencias físico-naturais ou da xeografía, salientando a importancia da percepción, da observación e da intuición. Aspectos plenamente integrados polos métodos activos.

Había naqueles anos oitenta do XIX sectores do profesorado, os de maior formación e titulación, en toda España iniciados e practicantes deste canon pedagóxico, incluídos os situados no campo da inspección escolar ou nas Escolas Normais do maxisterio, con intervención na incipiente publicística pedagóxica. Un profesorado que en ocasións era parte da "Institución difusa" e lector do Boletín de la Institución Libre de Enseñanza, que podía ter vinculacións masónicas e/ou liberais e republicanas. A través do republicanis$\mathrm{mo}^{15} \mathrm{e}$ da masonaría podían percibirse a filosofía hegeliana, o positivismo, o neokantismo

psicoloxía xenética e evolucionista. Vid: Dominique Otawi, De Darwin a Piaget. Para uma história da psicologia da criança (Lisboa: Instituto Piaget, 2004), 95-211, passim.

${ }^{11}$ Así 0 expuxo nos seus Principles of Psychology, na edición revisada de 1870, coa incorporación do darwinismo.

12 Pedro Alcántara García, La educación intelectual y los métodos de enseñanza (Madrid: Gras y Compañía editores, 1886).

${ }^{13}$ Pedro Alcántara García, Educación intuitiva y lecciones de cosas (Madrid: Gras y Compañía, 1881).

${ }^{14}$ Que tivo unha segunda edición en 1916 (Madrid: Librería de los Sucesores de Hernando).

${ }^{15} 0$ republicanismo decimonónico español expresouse, logo da curta experiencia republicana de 1873-1874, nunha tripla orientación (radical, reformista, federal), que deu paso en 1908 ao Partido Radical e desde 1912 ao Partido Reformista, á beira dos que conviviu a plataforma do krausoinstitucionismo, como con detalle e 
e 0 evolucionismo, que cultivaban os federalistas, os progresistas e os sectores krausistas (institucionistas), partidarios, por outra parte, da chamada educación popular, laica ou neutra, concibida como elemento fundamental de emancipación social e punto de partida da reforma social. ${ }^{16}$

Este xenérico enfoque da educación viuse fortalecido contra fins do século coa incorporación do intuicionismo bergsoniano e do pragmatismo de James e de Dewey. Sinala Morando que a doutrina bergsoniana sobre a "évolution créatice" e 0 "élan vital" "permitía saír da contradición en que estaba o naturalismo positivista, escindido entre a investigación das "leis científicas da educación e as constantes do desenvolvemento intelectual", dunha banda, e a realidade da experiencia que, pola outra, mostraba constantemente 0 espírito como un suxeito libre e activo e non sometido a esas leis. 0 "élan vital" ou impulso vital de todo individuo era fonte de liberdade e de autonomía, que escapaba de constantes e de leis. Este vitalismo naturalista introducía a idea dunha forza mobilizadora e espontánea que "impulsa a cada organismo a buscar en el ambiente circundante aquello que le ayuda a vivir mejor". ${ }^{17}$

0 que viña coincidir coa posición pragmatista deweyana, dinámica e funcionalista: toda persoa ten necesidades de vida e de desenvolvemento no seu contexto, que se expresan como intereses e nesta dirección o saber adquirido mediante a educación debería ser 0 que mellor responda ás necesidades e aos fins prácticos de quen aprende. Segundo isto - que pon o foco nos intereses-necesidades e no impulso vital-, un neno tamén experimenta a necesidade de crecemento biolóxico e psicolóxico e desde o punto de vista da formación cobra, daquela, fundamental importancia o principio da actividade.

A educación debería valerse, logo, dos intereses-necesidades como punto de partida, de modo que é responsabilidade do educador a tradución deses intereses-necesidades en intereses-guía do seu traballo formador, o que irá abrir o camiño para a "escola nova e activa". ${ }^{18}$ Dirá Claparède que "recoñecida esta necesidade [será responsabilidade dos educadores instrumentar] as actividades e as técnicas máis adecuadas para satisfacelas, ademais de estimular o desenvolvemento ulterior", ${ }^{19}$ motivo polo que falará dunha "école sur mesure", unha fórmula que, entre nós, explicou Domingo Barnés como unha "escuela adaptada a la personalidad del educando, fórmula fecunda que ha expoleado la observación y el estudio de esta personalidad infantil compleja e intensa, para liberarla de las férreas imposiciones de una educación uniforme". ${ }^{20}$

capacidade interpretativa se reflicte en Manuel Fernández Cortina, El gorro frigio. Liberalismo, Democracia, República (Madrid: Biblioteca Nueva, 2000), passim.

16 Ibid., 111.

${ }^{17}$ Dante Morando, Pedagogía, op.cit., 260.

18 Ibid., 271.

${ }^{19}$ Edouard Claparède, Psychologie de l'enfant et Pédagogie experimentale (Genève: Librairie Kundig, 1916, $6 .{ }^{\text {a }}$ edic.), 133.

${ }^{20}$ Domingo Barnés, La Paidología (Madrid: Espasa-Calpe, 1936), 19. 


\title{
Contra a "escola sentada" e en prol da "escola activa"
}

Nacía o novo século XX e a escritora sueca Ellen Key daba á luz un libro, case un manifesto, que fixo fortuna e que foi traducido ao inglés e editado en 1909 como The century of the child. A inquedanza por "outra educación" estaba presente entre distintos sectores sociais e encontraba terreo sementado entre sectores burgueses liberais, como se pon de relevo no dato de que en 1913 había 38 Escolas Novas afiliadas ao Bureau International de I'École Nouvelle e que cumprían cando menos 15 dos 30 puntos que Adolphe Ferrière trazara para elas, mostrando unha pedagoxía distinta canto aos valores que inspiraban a pedagoxía anterior ou tradicional. Escolas Novas onde se aprendía a través das propias experiencias infantís: "quen aprende é concibido como un axente dinámico, único e reorganizador, nun mundo de persoas e de cousas." 21

\begin{abstract}
En todas estas escuelas se encuentra entre los niños, segun Miss Ensor, una mayor alegría de vivir, más iniciativa, más imaginación y una inteligencia más abierta, porque la base de su educación es el desarrollo de los poderes internos y no la enseñanza de un cierto número de hechos relativos a un determinado número de materias. ${ }^{22}$
\end{abstract}

Eran, tamén, mostra desa inquedanza as novas revistas: $L$ 'École Renovée, que impulsara Ferrer i Guardia en 1908; L'École Emancipée, nacida no sindicalismo progresista do ensino en Francia en 1910; Pour I'Ere Nouvelle, que dirixirá Ferrière a partir de 1922, ou La Nouvelle Éducation con Cousinet (1922), ás que acompañaría en 1923 a Revista de Pedagogía dirixida por Lorenzo Luzuriaga.

Pode entenderse ben que Ernest Briod en 1917, como presidente da Sociedade Pedagóxica da Suíza francófona, ao presentar os temas do Congreso que en 1920 tería lugar en Neuchâtel, falara da école assise, como dun modelo para superar, e pouco despois Ferrière contrapoñerá a "escola activa" 23 á "escola sentada", onde se impartía un ensino abstracto e uniforme, para referirse "á actividade infantil que permite satisfacer unha necesidade, que se expresa baixo a forma dun interese." ${ }^{24}$ Porque non se trata dun "ac-

\footnotetext{
${ }^{21}$ En Wiliam Boyd, ed., Hacia una Nueva Educación. Relación y síntesis de los debates sobre la nueva psicología y el programa de la quinta conferencia mundial de la Asociación de la Educación Nueva celebrada en Elsinore (Dinamarca) en agosto de 1929 (Bilbao: Espasa-Calpe, 1931), 331. 0 texto foi traducido polo profesor galego Luís Gutiérrez del Arroyo, bibliotecario do Museo Pedagóxico Nacional.

${ }^{22}$ S.a., "La Escuela Nueva", en Diccionario de Pedagogía, ed. Luís Sánchez Sarto (Barcelona: Labor, 1936), T. I, 1196 .

${ }^{23} \mathrm{~A}$ fórmula de lécole active, que Ferrière difundiu, empregáraa por vez primeira Pierre Bovet en 1917 en L'Intermediaire des Educateurs, órgano do Institut Jean-Jacques Rousseau, na vez da fórmula "escola do traballo" que utilizara Kerchensteiner desde Munic, complementando a expresión "educacion funcional" que Claparède utilizou por vez primeira en 1905, baixo a influencia de Dewey. Vid. Adolphe Ferrière, L'école active (Neuchâtel/Genève, 2 Tt., 1922; V.a edición actualizada: 1947; Madrid: Beltrán, 1926, primeira edición española). Sobre a influencia desta obra na pedagoxía española vid. Joan Soler Mata, "La escuela activa de Adolfo Ferrière en la pedagogía española e iberoamericana", en Influencias suízas en la educación española e iberoamericana, ed. José María Hernández Díaz (Salamanca: Universidad, 2016), 69-82.

${ }^{24}$ Daniel Hameline, D. Jornod, M. Belkaïd, L'école active. Textes fondateurs (París: PUF, 1995), 12.
} 
tivismo escolar" sen máis ou da realización de accións escolares de ordinario indicadas polo profesor ou profesora, ou da man de manuais didácticos. Trátase de algo distinto:

La escuela no es activa porque el niño se mueva haciendo los ejercicios que, preparados por sus maestros desarrollan el programa, sino que es activa cuando es vital, cuando en ella el niño, como agente y sujeto principal, desenvuelve su vida plena y armonicamente, con autonomía, con libertad, en un ambiente adecuado en el que nacen espontaneamente sus intereses y donde hallan cumplida satisfacción, gracias a la cooperación y solidaridad de alumnos y maestros. ${ }^{25}$

Neste sentido, Ferrière expresaba que:

Confundir la escuela activa con los métodos activos significa un conflicto entre los principios de aquella y las exigencias de leyes escolares absurdas [...]. Los métodos activos son un procedimiento más, entre muchos otros, para hacer asimilar a los alumnos un programa establecido de antemano ${ }^{26}$, [pero] el programa de la escuela activa se basa sobre el interés psicológico del niño.Trata de seguir su desarrollo, de buscar sus necesidades en el momento en que se manifiestan, desenvolviéndolas y haciéndolas fecundas. ${ }^{27}$

Isto significa poñer o neno no centro das aprendizaxes, é dicir, basear as adquisicións escolares para construír o coñecemento sobre o seu desenvolvemento, concibindo a transmisión como unha extensión da experiencia infantil que é punto de partida; ${ }^{28}$ e será bo recordar que poñer o neno no centro dos procesos educativos foi a proclama do Institut Jean-Jacques Rousseau en 1912, co seu lema Discat a puero magister, isto é, "que o mestre aprenda do neno".

Con estes modos foi afirmándose a presenza de escolas diferentes nas distintas xeografías internacionais, foron véndose innovacións tamén nalgunhas escolas públicas e foron creándose as escolas-xardín e as escolas-granxa, as escolas ao aire libre ou de bosque, ou tamén a "escola produtiva" ${ }^{29}$ como formas de escola activa. Por isto, Luzuriaga percibía en $1932^{30}$ distintas modalidades escolares: a tradicional intelectualista e memorista; a tamén tradicional, pero con prácticas e exercicios (como problemas e redaccións); as que incorporaban algunhas actividades físicas, técnicas e volitivas, mediante a práctica de xogos, traballos manuais, excursións, dramatizacións; e aqueloutras escolas nas que a actividade infantil xurdía dos propios nenos (autoactividade) ou esta era suxerida. E facía notar que as "escolas novas" acollían estas dúas modalidades, e mellor esta última, ao incorporar de xeito integrado as actividades físicas e as técnicas.

\footnotetext{
${ }^{25}$ S.a., "La Escuela Nueva", en Diccionario de Pedagogía, ed. Luís Sánchez Sarto (Barcelona: Labor, 1936), T. I, 1193.

${ }^{26}$ Adolphe Ferrière, La ley biogenética y la escuela activa (Madrid: Publicaciones de la Revista de Pedagogía, 1928), 20.

${ }^{27}$ Ibid., 80

${ }^{28}$ Marie-Claude Blais, Marcel Gauchet, Dominique Otawi, Conditions de l'Éducation (París: Fayard/Pluriel, 2010), 228.

${ }^{29}$ Lorenzo Luzuriaga, Concepto y desarrollo de la nueva educación (Madrid: Publicaciones de la Revista de Pedagogía, 1932, 2a edición renovada),77.

${ }^{30} \mathrm{Ibid}$., 28-29.
} 
Na forma de caracterización, o mesmo Luzuriaga distinguía: as "escolas novas", propiamente ditas e de carácter privado, as "escolas experimentais" (case sempre ligadas a ámbitos universitarios), as "escolas activas" e "as escolas de ensaio e reforma".

Un panorama que comezaba a estar tamén presente nunha España en proceso de modernización e de urbanización, se ben con profundas desigualdades sociais e territoriais, e que vivía desde os anos dez intensos procesos de cambio, non exentos de graves conflitos sociais e de ideas, sendo escenario, á súa vez, de demandas, de propostas e de iniciativas no campo escolar e educativo. Igualmente comezaba a apreciarse aquí a presenza de modos didácticos propios das novas orientacións.

Interviñan neste proceso favorecéndo0, a ILE, a oficial Xunta de Ampliación de Estudos e de Investigacións Científicas (a coñecida JAE), como vía de europeización pedagóxica e creada en 1907;31 e a "Escuela de Estudios Superiores del Magisterio", ${ }^{32}$ creada en 1909 como centro de formación docente (de alumnos-mestres) de quen serían as e os inspectores de educación primaria e o profesorado das Escolas Normais en toda a xeografía española, entre outras instancias. Ademais, contribuíron tamén á renovación do plan de estudos para a formación do profesorado primario en 1914, ${ }^{33}$ con intensificación da súa formación pedagóxica e didáctica, e a creación do "Instituto-Escuela" en 1918 como centro de experimentación de reformas curriculares para o ensino secundario, sendo adecuado aludir, por fin, ao labor editorial, ${ }^{34}$ ao se traduciren textos pedagóxicos que, con relativa prontitude, trasladaron aquí textos orixinalmente editados en francés, en inglés ou en alemán, para responder así ás novas correntes psicopedagóxicas.

Galicia non estaba ausente destes procesos. Falamos dunha comunidade social con forte identidade cultural e lingüística popular - de algo máis de dous millóns de habitantes, cunha porcentaxe de poboación agraria próxima ao $90 \%$, con pouco máis do $10 \%$ de habitantes que vivían nas pequenas cidades e vilas históricas, con algunhas factorías industriais e un esluído sector terciario. Entre os anos dez e trinta tamén aquí están

\footnotetext{
${ }^{31}$ Institución oficial que canalizou un dinámico programa de axudas para a realización de viaxes e estadías de estudo en Europa (non só), que fixo posíbel que ata 1936 preto de 2000 docentes españois (e galegos) tiveran ocasión de entrar en contacto directo con institucións educativas e culturais de todo o continente e puideron observar, analizar e valorar o que acontecía noutros países, cara a achegar aquelas perspectivas xulgadas valiosas.

32 Vid. Salvador Ferrer C. Maura, Una institución docente española. La Escuela de Estudios Superiores del Magisterio (1909-1932). (Madrid: Cedesa, 1973) e Antonio Molero Pintado, María del Mar del Pozo Andrés (eds.), Escuela de Estudios Superiores del Magisterio (1909-1932) (Alcalá de Henares: Servicio de Publicaciones de la Universidad, 1989). A formación curricular, na que interviñan profesores destacados, incluía desde 1917 a existencia de seminarios pedagóxicos e científicos, a organización de prácticas de ensino, ciclos de conferencias, excursións e colonias; 0 alumnado finalizaba o seu ciclo de catro cursos de formación coa presentación dunha Memoria de fin de carreira.

${ }^{33}$ Con tres anos de formación para todos e ata catro cursos para a obtención do título de mestre superior.

${ }^{34}$ Deberemos mencionar as edicións de La Lectura, Beltrán, Espasa-Calpe, Hernando ou Daniel Jorro, todas de Madrid, ademais das imprescindíbeis Publicaciones de la Revista de Pedagogía, e as da Casa Labor de Barcelona
} 
presentes diversos conflitos obreiros e campesiños (con notábel mobilización agraria), ao tempo que se rexistra unha grande emigración ás terras de América: ${ }^{35}$ un escenario conflitual e con actores mobilizadores das mentalidades. Entre a memoria do republicanismo federal e o republicanismo radical ou reformista; con algúns sectores liberais, uns gromos anarco-socialistas e desde 1916 afirmaríase a articulación do rexionalismo político e cultural, a través do impulso das Irmandades da Fala, que terminaría xerando un discurso de nacionalismo político galego favorábel á autonomía política de Galicia. Con todo isto, desde Galicia participaríase igualmente no proceso de transformación escolar.

\title{
A afirmación do modelo da Escola Nova
}

Chegados a este punto, debemos preguntarnos se é posíbel realizar unha estrita definición destas Escolas Novas e Activas? Semella que non na altura dos anos trinta, de considerar a cualificada opinión de Luzuriaga, quen era o representante español da Ligue Internationale de I'Éducation Nouvelle (LIEN) e editor do seu órgano de expresión en lingua castelá, a Revista de Pedagogía, que acompañou con varias coleccións de textos agrupados baixo o rótulo "Publicaciones de la Revista de Pedagogía" ${ }^{36}$ Di Luzuriaga:

\begin{abstract}
Hoy por hoy, no existe todavía, una definición, una expresión sintética de lo que esa 'educación nueva' sea. Existen, si, tendencias, agrupaciones, escuelas 'nuevas'; pero no una teoría, una elaboración sistemática de esa educación. [...] Si quisiéramos encontrar un punto concreto de partida para la actual 'educación nueva', habríamos de buscarlo a nuestro juicio, en el gran pedagogo norteamericano John Dewey [...], que rompe con la tradición herbartiana e inicia con sus obras y sus instituciones la actual educación nueva. Casi simultaneamente e independientemente quizás de sus ideas, surgían en Europa las primeras escuelas nuevas inspiradas por ideas románticas y vitalistas. Posteriormente surgieron los pedagogos representativos como Kerchensteiner, Clàparede, Wyneken, Cousinet, Ferrière, Montessori o Decroly.[...En todo caso e sintetizando o que Luzuriaga expón] a concepción nova da educación pode caracterizarse arredor dos seguintes trazos: o principio da autoactividade, a idea de vitalidade, o principio da liberdade (didáctica e moral), o recoñecemento da substantividade da infancia e a idea de comunidade. ${ }^{37}$
\end{abstract}

En 1932, coincidindo con Luzuriaga, expresábase nos seguintes termos o profesor galego Gerardo Rodríguez García, que era o director da revista pedagóxica La Escuela Moderna:

\footnotetext{
${ }^{35}$ Alí, en numerosas ocasións, ocorría a transformación das mentalidades tradicionais no contacto co mundo urbano, coa democracia política, co liberalismo ou co socialismo, e tamén no contacto con sectores da intelectualidade galega asentada naquelas repúblicas logo do fracaso da Primeira República española e de América virán pouco a pouco ventos de liberdade e de republicanismo a través da correspondencia familiar, dos retornos, das publicacións e dos libros que se traían.

${ }^{36} 0$ pedagogo Lorenzo Luzuriaga é amplamente recoñecido non só en España, senón tamén na Arxentina, país ao que se exiliou politicamente en 1936, e no Brasil. Foi motivo dalgúns valiosos estudos; en particular, citamos aquí o elaborado polo profesor galego, que fora director desta revista Sarmiento na súa primeira etapa, Herminio Barreiro Rodríguez, Lorenzo Luzuriaga y la renovación educativa en España (1889-1936) (Sada: Ediciós do Castro, 1989).

${ }^{37}$ Lorenzo Luzuriaga, Concepto y desarrollo de la nueva educación (Madrid: Publicaciones de la Revista de Pedagogía, 1932, 2. ${ }^{a}$ edición renovada), 30-34.
} 


\begin{abstract}
La diversidad de las Escuelas Nuevas tiene origen, tanto en la variedad de las circunstancias en que cada una de ellas se organiza y vive, como en el predominio que en unas y otras alcanzan determinadas finalidades, y en las diferencias que existen entre las doctrinas pedagógicas de los autores más prestigiosos, pues no hay entre ellos acuerdo completo en la apreciación de todas las cuestiones que en el terreno de la educación se plantean. Por otra parte, las Escuelas Nuevas son verdaderas escuelas de ensayo, ya que en ellas se ponen en práctica principios y normas que sólo habían tenido valor teórico.

[Por eso, nuestro] Es imposible dar una definición o descripción característica de la "Escuela Nueva", pues entre los establecimientos que se han asignado este título tan sugerente existen muy grandes diferencias. La nota que se puede señalar como más común a todas ellas es la de su actuación en aplicación práctica de las doctrinas de la Pedagogía Moderna a la educación de grupos de muchachos, constituidos en comunidades escolares con tendencia a una formación, no predominantemente intelectual, como sucede todavía en casi todos los establecimientos de enseñanza, sino integral, es decir, que abarque todos los aspectos esenciales de la vida humana. ${ }^{38}$
\end{abstract}

Estas foron, en efecto, as notas que guiarían a actuación pedagóxica dun número crecente de mestres e mestras presentes nas escolas públicas, sobre todo nos avanzados anos vinte, como se valorou con ocasión da edición das actas do congreso da LIEN realizado en Elsineur en 1929:

Vino el tercer momento de este movimiento cuando los maestros de las escuelas públicas, inflamados por las ideas y los impulsos de los grandes pensadores, inspirados por lo que se estaba haciendo en las escuelas de vanguardia, pusieron en práctica en sus escuelas las ideas nuevas [...] Los maestros empezaban a preguntarse si lo que ellos estaban enseñando era digno de enseñarse, y si, en todo caso, no podía ser puesto en forma más vital para el niño. ${ }^{39}$

Coa preocupación de extensión desta nova filosofía educativa, Lorenzo Luzuriaga propuxera en 1928 unha re-consideración dos 30 puntos cara á súa asunción por parte das escolas públicas, sinalando no primeiro deles:

A escola pública renovada é un laboratorio de pedagoxía experimental.

1. Goza dunha ampla autonomía no seo da organización do ensino oficial e ensaia os novos métodos pedagóxicos antes de que estes sexan aplicados nas demais escolas públicas.

Apóiase sobre os datos da psicoloxía infantil e sobre as demais ciencias que fundamentan a pedagoxía (filosofía, socioloxía, bioloxía).

2. Procura intensificar o desenvolvemento da vida infantil en todas as súas manifestacións (físicas como espirituais) sen outra finalidade transcendental ou utilitaria. $^{40}$

${ }^{38}$ Gerardo Rodríguez García, "Las Escuelas Nuevas”, La Escuela Moderna, 487 (1932): 146.

${ }^{39}$ En Wiliam Boyd, ed., Hacia una Nueva Educación.Relación y síntesis de los debates sobre la nueva psicología y el programa de la quinta conferencia mundial de la Asociación de la Educación Nueva celebrada en Elsinore (Dinamarca) en agosto de 1929 (Bilbao: Espasa-Calpe, 1931), 171.

${ }^{40}$ Lorenzo Luzuriaga, "Les trente points caractéristiques de l'École publique renovée", Pour I'Ére Nouvelle, 40 (1928) 146. Luzuriaga fixo unha tradución en español deste texto, que publicou en Lorenzo Luzuriaga, La Escuela Nueva Pública (Buenos Aires: Losada, 1965), 20-33. 
No Congreso da LIEN que tivo lugar en Niza en 1932 asignáselle á educación, ademais, a tarefa de formar cidadáns do mundo, de preparar a infancia para entender as complexidades da vida social e económica e de construír unha xeración nova para o novo mundo: "A Escola Nova debe preparar, en cada neno, o futuro cidadán, capaz de cumprir non só os seus deberes para coa patria, senón tamén para coa humanidade". Esta foi a mensaxe que quedou para o futuro; unha mensaxe que trasladada ao presente adopta esta expresión:

A educación nova consiste en favorecer o desenvolvemento tan completo como posíbel das aptitudes de cada persoa, á vez como individuo e como membro dunha sociedade rexida pola solidariedade. A educación é inseparábel da evolución social; pois constitúe unha das formas que a determinan. 0 fin da educación e dos seus métodos debe, pois, ser constantemente revisado, a medida que a ciencia e a experiencia fan crecer o noso coñecemento do neno, dos seres humanos e da sociedade. ${ }^{41}$

\section{En favor dunha pedagoxía científica e do activismo metodolóxico en Galicia}

En 1887 a recentemente creada "Asociación Pedagógica de Maestros de Pontevedra" convocaba, baixo a presidencia de Eugenio Montero Ríos, ${ }^{42}$ un "Congreso Pedagógico Regional”, que seguía ao primeiro Congreso Pedagóxico Nacional español de 1882; exercía como secretario del Enrique García Requejo, profesor e impulsor desde 1880 da escola Froebel de Pontevedra ${ }^{43}$ e desde a súa experiencia expresaba:

En las escuelas froebelianas se investiga, se observa, se compara, se analiza y después se juzga y se interroga, siendo la respuesta final el resultado de los raciocinios formados sobre el objeto mismo ${ }^{44}$ [...]

La educación o la enseñanza es nula si se le impide al niño moverse libremente en la esfera de su acción, violentándole, oprimiéndole y coartando su libertad, porque la violencia engendra el odio, la mentira y la aversión; la opresión supone la negación del afecto, y la privación de la libertad anodada, debilita y llama siempre a la fuerza y a la resistencia, justas porque la libertad cae bajo las leyes del derecho y sagradas porque el hombre fue creado para la libertad. En toda buena educación, en toda verdadera enseñanza deben ser, pues, aseguradas en el niño, la libertad y la espontaneidad. ${ }^{45}$

Pode ser este un bo punto de partida deste relato. E non pode faltar aquí a referencia ao médico Joaquín E. García Sánchez, ${ }^{46}$ que á fronte dunha sociedade de profesores dirixía en 1902 o denominado "Colegio privado de segunda enseñanza" de Betanzos,

\footnotetext{
${ }^{41}$ Marie-Christine Chycky et Jacques George, "L éducation toujours nouvelle”, Les Cahiers Pédagogiques, 395 (2001): 3.

${ }^{42}$ Presidía quen fora republicano e era, en todo caso, liberal progresista ademais de figura destacada da ILE.

${ }^{43}$ Algunhas indicacións, que non puidemos confirmar, aluden á influencia que nesta creación tivera o profesor Federico Saiz, catedrático da Escola Normal pontevedresa vinculado á ILE. Federico Saiz será pai do destacado intelectual pontevedrés, republicano e teósofo, Victor Saiz Armesto (1871-1914).

${ }^{44}$ Enrique García, Froebel y su sistema de educación (Pontevedra: Imprenta de la Vda. e Hijos de Madrigal, 1887), 14-15.

45 Ibid., 13.

${ }^{46}$ Fixemos mención deste autor en Antón Costa. "Darwinismo, Evolucionismo e Pedagoxía", en 0 darwinismo en Galicia, ed. Francisco Díaz-Fierros Viqueira (Santiago: Servizo de Publicacións da Universidade de Santiago, 2009), 204.
} 
sendo el autor en 1896 do Ensayo de la aplicación de los conocimientos fisiológicos al mejoramiento de la educación moral e intelectual del hombre ${ }^{47}$; érao tamén do regulamento do centro e mais dun escrito complementario sobre o método didáctico, do que entresacamos:

Art. 49. Siendo la enseñanza intuitiva, se hará tomar parte al alumno en la investigación científica, acostumbrándole a la observación. Como ampliación del método activo se pondrán en práctica las excursiones, visitando fábricas, escuelas, talleres, etc., haciendo ejercicios de aplicación de los conocimientos adquiridos, midiendo terrenos, levantando planos, recogiendo y clasificando, ya productos naturales, ya industriales.

Art. 50. Se procurará además que los señores alumnos, y aún los profesores para dar ejemplo, construyan por si mismos algún aparato, dibujen alguna carta o saquen de algún modo cierto provecho de sus ejercicios prácticos, haciendo aplicación de los conocimientos teóricos aprendidos.

Del método: El profesorado procura emplear el método activo en todas las enseñanzas. El esfuerzo interior del educando se cree un factor indispensable para obtener un resultado favorable en la educación y cultura del mismo; [...] huyese, cuanto es buenamente posible, de toda enseñanza dogmática, mecánica y verbalista que, matando toda espontaneidad en el educando y privándole del goce que su cooperación interior y reflexiva ha necesariamente de producirle, da por resultado una instrucción más bien de palabras que de ideas a las cuales corresponda algo real y positivo en la naturaleza. [...] Hacer que los alumnos observen la naturaleza y las cosas, con preferencia a los signos que las representan, que discurran sobre los datos obtenidos, bien de palabra, ya por escrito, es la tendencia general del profesorado, que procura emplear con preferencia la forma socrática de enseñanza, sin desdeñar por eso la meramente expositiva, aunque en forma de conversación familiar, más bien que de discurso dirigido, como de ordinario, a una multitud anónima. ${ }^{48}$

Estamos, sen dubidalo, ante textos portadores de nova pedagoxía. En Betanzos debeu forxarse o mestre Darío Caramés Ruza, que desde 1896 exercía na escola de Santo Domingo, desde a que promovía a revista infantil Infancia, mantiña correspondencia interescolar, creaba un museo escolar con traballos manuais dos nenos e realizaba excursións escolares a distintos lugares de observación, levando a cabo un ensino práctico e obxectivo. Este mestre accedería á Inspección escolar en 1920 con destino en Biscaia, de onde pasará a exercer en Madrid como inspector xeral de colonias escolares. ${ }^{49}$ Coma 0 caso do profesor Caramés, outros profesores deberon sentirse chamados por un ensino positivo e intuitivo; puido ser 0 caso de José M. ${ }^{a}$ Lage Martínez, das terras de Ortigueira (1862-1930) quen logo de obter 0 título de mestre superior en Madrid, accedeu á docencia en Ortigueira, onde impulsou o xornal infantil El Escolar entre 1905 e 1907 con 23 números - que serviu de exemplo para outra publicación igualmente escrita polos nenos, El Faro de Veiga, con 61 números - ${ }^{50}$ e logrou en 1910 a graduación das escolas

\footnotetext{
${ }^{47}$ A Coruña: La Voz de Galicia.

${ }^{48}$ Vid. Antón Costa, "A presencia da Institución Libre de Enseñanza en Betanzos", Anuario Brigantino, 11 (1988): 61-68.

${ }^{49}$ Vicente Abarrategui Paradela, "Darío Carames", Anuario Brigantino, 3 (1951) 132.

${ }^{50}$ Vicente Peña, "El pulso de la vida. Narrativas y representaciones de la cotidianeidad en la primera prensa escolar infantil de Galicia (1905-1913)", en La prensa de los escolares y estudiantes. Su contribución al patrimonio histórico-educativo, ed. José María Hernández (Salamanca: Ediciones Universidad de Salamanca, 2015), 143-164.
} 
desta vila, que se converteron nas primeiras escolas graduadas da provincia da Coruña e que el mesmo dirixiu ata a súa xubilación en 1923.

Nesta perspectiva están os libros de texto que no Uruguai preparaba o profesor galego, masón, republicano federal e exiliado, Francisco Vázquez Cores (Ferrol, 1848-Montevideo, 1914), ${ }^{51}$ un dos fundadores do Centro Galego de Montevideo e colaborador de El Eco de Galicia e de La Unión Gallega, importante autor de libros de texto - de Historia, Xeografía, Xeoloxía, e Historia Natural- ademais de editor e libreiro no campo da educación, ${ }^{52}$ desde 0 que contribuíu ao éxito da reforma educativa de José Pedro Varela, promotora do intuicionismo e do positivismo, que puido dicir: "He enseñado a mis alumnos el amor a la humanidad, a la libertad, a la patria, a la ciencia y al estudio; horror a la tiranía, al fanatismo y a la intolerancia. Abnegación y austeridad hasta el sacrificio" . ${ }^{3}$

Desde as terras arxentinas chegaron as influencias doutro destacado profesor galego, Ignacio Ares de Parga, quen gozou de considerábeis contactos coa ILE e co republicanismo federal hispano, incluso despois da súa instalación na Arxentina, como docente e pedagogo con algún recoñecemento. ${ }^{54} \mathrm{Na}$ Arxentina situábase no ronsel e amizade de figuras como Juan G. Beltrán e outros educadores situados no espazo do liberalismo reformador de ascendencia deweyana, desde onde guiaba os criterios de actuación que se seguían nas Escolas da Unión Hispano-Americana pro Valle Miñor, sen dúbida un dos espellos expresivos da influencia da Escola Nova en Galicia ao longo dos anos dez e vinte do século XX.

A Pontevedra decimonónica, a Boa Vila, contaba con algunhas figuras ligadas ao republicanismo federal e ao campo cultural e da formación, que terminarán conectando co radical-lerrouxismo durante 0 século XX. Nese núcleo o matrimonio Laureano Poza Estévez/Casilda Cobas Juncal terá un singular destaque: ${ }^{55}$ a través dos seus fillos e dos enlaces familiares realizados veremos inflexións na medicina, no xornalismo e na educación. Celestino Poza Cobas dirixirá desde 1903 o colexio "La Escuela Moderna”, que daba acollida a unha ensinanza integral, teórico-práctica, con presenza do debuxo, o canto, os xogos escolares, as leccións de cousas, os paseos, a ximnasia e as disertacións escolares. ${ }^{56}$ Joaquín Poza Cobas será, pola súa parte, o director de La Libertad desde 1906;

\footnotetext{
${ }^{51}$ Antón Costa, Uxía Bolaño Amigo, "Galería de profesorado galego en América nos séculos XIX-XX (Arxentina, Uruguai, Cuba)", Anuario Brigantino, 40 (2017): 219-246.

${ }^{52}$ En 1883 abriu o estabelecemento Librería Universal co apoio do tamén galego Antonio Barreiro Ramos e cuxa propaganda incluía regularmente esta indicación: "Toda persona puede entrar en esta librería, tomar los libros de los estantes y sin pedir permiso revisarlos uno por uno y retirarse sin comprar nada. Lectura de balde. Casa única en su jénero (sic).

${ }^{53}$ Francisco Vázquez Cores, “Digna actitud”, La Unión Gallega, 61 (1882): 160-161.

${ }^{54}$ Xosé Manuel Malheiro, "A influencia do contexto educativo arxentino na Unión Hispano-Americana Valle Miñor a través do pedagogo Ignacio Ares de Parga", en Emigración e Educación (1900-1936). I Centenario das Escolas da Unión Hispano-Americana Valle Miñor (1909-2009), coord. Xosé Manuel Malheiro (Nigrán/ Gondomar: Instituto de Estudos Miñoranos, 2011), 297-319.

${ }_{55}$ Carlos Pereira Martínez, "A Familia Poza. Un exemplo de republicanismo e librepensamento en Pontevedra", Anuario Brigantino, 27 (2004), 265-312.

${ }^{56}$ Quizais se puideran estabelecer algunhas vinculacións entre este centro pontevedrés, impulsado polo republicano e masón Celestino Cobas, con "La Escuela Moderna" de Ferrer en Barcelona, o que de momento
} 


\section{LH ESCUIELA MODERNA}

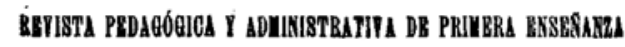

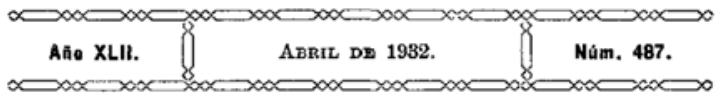

\section{LAS «ESCUELAS NUEVAS»} Y LOS PEDAGOGOS DE LA «NUEVA EDUCACIÓN» (1)

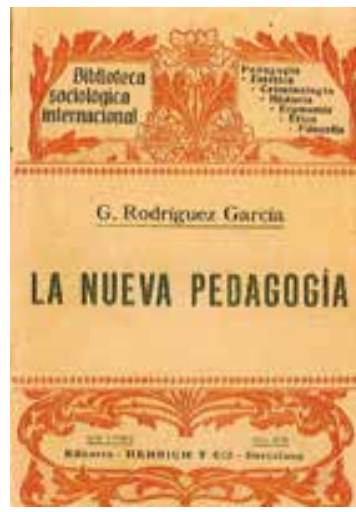

0 profesor compostelá Gerardo Rodríguez propiciou tanto cos seus textos propios como a través da dirección da revista La Escuela Moderna a aclimatación das novas referencias educativas en España.

casou con Pilar Juncal Berdulla, irmá de José Juncal Berdulla, profesor da Escola Normal de Pontevedra e director do xornal La Unión Republicana, entre outros medios de prensa, que pasou en 1910 a ser profesor da Escola Normal de Barcelona, e aquí foi concelleiro da cidade polo Partido Radical, impulsor da renovadora Escola del Bosc á altura de 1914 e das colonias escolares ${ }^{57}$ e tamén director desta Escola Normal entre 1920 e 1932. Un dos fillos do matrimonio arriba referido, Hernán Poza Juncal, foi entre 1924 e 19290 director da "Escuela Hospital Asilo" de Lalín fundada polos emigrantes galegos en América con criterios de "escola nova", ${ }^{58}$ logo continuados a partir de 1930 por este citado profesor ao impulsar na cidade de Pontevedra o centro "La Escuela Nueva".

Deberemos facer algunha referencia a José Gutiérrez del Arroyo Cebreiro, quen ao nacer 0 século XX pasou desde Galicia a Madrid para ser un destacado profesor da escola da ILE, ao tempo de ser referencia precisa nas colonias escolares da ILE en San Vicente de la Barquera (Santander), pero tamén nas da Coruña desde 1902. Canda el, un seu

debemos deixalo en hipótese de traballo. Celestino Poza era en 1903 mestre superior e licenciado en Medicina e Cirurxía. Sabemos que 014 de outubro asina a solicitude de autorización para pór en marcha este colexio con dous salóns de clase no primeiro andar e un salón de ximnasia —na planta baixa na rúa Andrés Muruais, 6 -, equivalente en extensión aos dous salóns superiores. No plan de estudos presentado non aparecen nin a materia de Relixión nin a de Historia Sagrada. Con data do 24 de outubro de 1904 o colexio foi visitado polo inspector de educación da provincia de Pontevedra, Ignacio Covelo Álvarez, quen no seu lacónico informe só dirá: "hallándolo ajustado en todo a lo que la Pedagogía moderna aconseja". Vid. Caixa S. H., 233, Expte. 37, Educación Primaria, Arquivo Histórico da Universidade de Santiago de Compostela.

${ }^{57}$ María Luisa Gutiérrez, "Aproximación a un espacio educativo: la Residencia de estudiantes normalistas de la Escuela Normal de Maestros de Barcelona (1923-1934)", Revista de Educación, 323 (2000): 331 e nota a pé num. 40.

${ }^{58}$ Antes e despois da experiencia lalinense, Hernán Poza Juncal andou por Barcelona, protexido por José Juncal. En terras catalás semella ter participado nunha escola ao aire libre, "Nuestra escuela", en Hostalric, e que exerceu como profesor da Residencia de Estudantes Normalistas da Escola Normal de Mestres, antes de retornar a Pontevedra, onde funda "La Escuela Nueva", que dirixiu ata 1936. 
irmán, Luís, sería outro dos profesores galegos da ILE, encargado do Servizo da Biblioteca do Museo Nacional, ${ }^{59}$ onde igualmente exerceu as responsabilidades de secretario e de dirección.

\section{Un autor singular: Gerardo Rodríguez García e a Nova Pedagoxía}

Procede achegarnos á figura deste mestre compostelán (1873-Madrid ?), con título superior obtido na Escola Normal Superior de Santiago de Compostela, docente contra fins de século e inicios do XX na escola primaria de Sar nesta cidade. Un mestre intelectualmente esixente, rexeneracionista, reformador de espírito positivista e publicista no campo da educación primaria, que saltará desde as páxinas da prensa local á edición de numerosas monografías de materia educativa, nas que deixa ver a súa formación como didacta e metodólogo, aberto ás correntes internacionais da educación, aínda que con algún abuso dun estilo retoricista que acocha algunha falta de claridade no seu pensamento, ao ir alén das aplicacións didácticas. En 1906 publica en Barcelona, na prestixiosa Biblioteca Sociolóxica Internacional, o texto La Nueva Pedagogía, aludindo á nova pedagoxía científica asentada no desenvolvemento psico-fisiolóxico da natureza infantil e en 1908 aproba a oposición a escolas superiores en Madrid, cidade desde onde exercerá con maior resonancia ata chegar a alcanzar en 1914 a presidencia da Asociación Nacional del Magisterio Primario. En 1920 pasará a exercer ata 1934 a dirección da prestixiosa publicación periódica La Escuela Moderna, ${ }^{60}$ a revista pedagóxica que fundara no XIX 0 recoñecido pedagogo Pedro Alcántara García e dirixe o grupo escolar graduado Enrique de Mesa, ata o momento da súa xubilación en 1942.

Na súa vigorosa prosa de 1903 encontramos formulacións como as seguintes, inhabituais noutros docentes de Galicia:

En Pedagogía debemos dar por pasado, muerto y sepultado el período romántico y declamatorio. Pedagogía elocuente y utópica, tenemos ya de sobra. Hoy habremos de buscar otra cosa, si queremos hacer algo de provecho, algo que corresponda al estado actual de los conocimientos científicos [...] Nadie tiene hoy derecho á escribir sobre asuntos pedagógicos, ignorando en absoluto todo lo que se ha trabajado en la investigación fisiológica y psicológica en los últimos cien años. ${ }^{61}$

En 1920 ao facerse cargo da dirección de La Escuela Moderna formulaba as súas intencións ao indicar que, sen descoñecer o papel da filosofía educativa, era o momento da chamada "pedagoxía científica", como xa expresara en 1906, nos seguintes termos:

\footnotetext{
${ }^{59}$ Vid. nota 21.

${ }^{60}$ No noso texto Escolas e Mestres (1989) referímonos a esta figura, sen chegar a estudala. Hai só un achegamento analítico, aínda insuficiente, á obra deste autor, realizado por Soledad Montes Moreno, como consecuencia do estudo bibliométrico e teórico da publicación La Escuela Moderna realizado na súa tese de doutoramento en Ciencias da Educación. Soledad Montes Moreno, "Aproximación bibliográfica y profesional a la figura de Gerardo Rodríguez García, impulsor del asociacionismo del magisterio", Sarmiento. Anuario Galego de Historia da Educación, 3 (1999):183-204.

${ }^{61}$ Gerardo Rodríguez García, "Pedagogía engañosa”, La Escuela Moderna, 150 (1903):175. Así escribía en 1903, criticando a que consideraba verborrea do Padre Manjón, o impulsor das "Escuelas de Ave María", unha proposta católica de intervención educativa.
} 
Al hablar de Pedagogía científica, se ha de entender concretamente una Pedagogía que plantea los problemas prácticos de la educación tomando como punto de partida hechos reales, vistos a la luz de la Fisiología y de la Psicología contemporáneas; que estudia estos problemas siguiendo métodos y orientaciones conformes con el criterio de la Biología; que emplea los medios de investigación propios de estas ciencias; que no se limita a examinar los aspectos más generales de las cuestiones pedagógicas, sino que analiza los detalles todos, elementos esenciales en una obra práctica, como lo es esta de la acción educadora.

Basada esta dirección, fundamentalmente, en los frutos recientes de la Psicología y de la Fisiología, en las concepciones nuevas de la Biología y la Sociología, era necesario que los resultados de todas estas investigaciones científicas, y aun los criterios y métodos de ellas, se vulgarizasen en cierta medida y llegasen a interesar a los pedagogos y educadores, para que éstos comprendiesen la importancia que tienen tales métodos e investigaciones en relación con la Pedagogía; para que viesen en ellos las bases de una actitud nueva del investigador frente a los problemas de la educación; para que se diesen cuenta siquiera de la inconsistencia de las doctrinas pedagógicas generalmente admitidas como buenas, y de la ineficacia de los medios, métodos, procedimientos y líneas directivas que, en términos filosóficos, se ofrecían a los educadores como normas para su trabajo profesional.

No se trata, en esta tendencia pedagógica, de condenar la Filosofía, ni aún la más abstracta Metafísica. Pero la Filosofía tiene otro campo de aplicación, otro valor mental, social y civilizador que el de crear una técnica directiva del trabajo pedagógico. No se trata de desconocer la importancia de los servicios prestados a la Pedagogía por los filósofos. Ellos han creado la aspiración educativa, la han alimentado, la han rodeado de una aureola sugestiva de idealidad, y han cultivado y disciplinado la tendencia pedagógica, fuerza social que hoy aparece en todo el mundo culto, en corriente cada dia más vigorosa. Pero ya, en beneficio de esta obra que ellos han sabido iniciar y han hecho vislumbrar y amar a los pueblos, deben dejar el campo a los obreros, de más modestas aspiraciones, del trabajo científico paciente, minucioso, a quienes corresponde definir, concretar qué es lo que hay de realizable en los ideales diversos tan brillantemente presentados por la Pedagogía filosófico-literaria. ${ }^{62}$

\section{Eloy Luís André e outros profesores como mensaxeiros dun tempo educativo novo}

A Galicia - espazo con reducida topografía urbana, como indicamos - chegaron informacións sobre "o novo" en educación por diversas vías: a destes profesores "adiantados" que mencionamos; a información recibida desde Madrid por vías académicas, periodísticas e políticas a través de viaxeiros e profesores que van e veñen; por medio da vía americana daqueles que foran a América como emigrantes e en ocasións como expatriados de carácter político que trouxeron de volta novas imaxes sobre a educación; ${ }^{63}$ e, igualmente, a través das visitas de estudo realizadas a distintos destinos europeos, mediante as convocatorias de bolsas realizadas pola JAE, sobre todo despois de $1910 .{ }^{64}$

\footnotetext{
${ }^{62}$ Gerardo Rodríguez García, "De la pedagogía filosófica a la pedagogía científica”, La Escuela Moderna", 1-2 (1920): 6-7.

${ }^{63}$ Asunto que desenvolvemos distintos investigadores ao falar das escolas creadas en Galicia polos emigrantes galegos e ao falar da relación Galicia-América.

${ }^{64} \mathrm{~A}$ este respecto, Teresa Marín Eced, anota os nomes dos pensionados galegos (homes e mulleres) ou daqueles que sen seren pensionados gozaron da "condición de pensionados" en Innovadores de la educación en España (Becarios de la JAE) (Cuenca: Ediciones de la Universidad de Castilla-La Mancha, 1991). A Xunta para a Ampliación de Estudos, creada en 1907 e activa sobre todo desde 1910 concederá ata 1936 un total de 1700 bolsas de estudo; delas 188 como pensións individuais e 75 na modalidade de pensións "en grupo" no campo da formación pedagóxica, unha parte delas para profesorado e investigadores de Galicia. Para o caso específico
} 
Adiantado foi o profesor ourensán Eloy Luís André, quen logo de doutorarse na Universidade de Salamanca foi enviado pola Administración española en 1906 a varios países europeos para estudar as súas reformas educativas; cando xa comezara a formar un modesto laboratorio de psicoloxía experimental no Instituto de Ourense, gozou doutra bolsa de estudos para viaxar a Alemaña (Leipzig e lena) durante os cursos 1910-1911 e 1911-12, onde obtivo unha alta formación filosófica e no ámbito da psicoloxía experimental, que considerou nos seus numerosos textos e monografías. En 1913 foi de novo pensionado co fin de redactar unha memoria sobre os estudos de segundo ensino, para o que visitou centros de Francia, Bélxica, Alemaña e Suíza, e foi, ademais, invitado en 1914 pola comisión organizadora para participar no Congreso Internacional de Educación Popular desenvolvido en Leipzig. Así, puido dar conta en 1916 en Educación de la Adolescencia $^{65}$ do amplo movemento de nova educación que Alemaña viña rexistrando desde finais do século XIX, o que o levou a caracterizar estas escolas como "templo y taller, laboratorio y jardín"66:

Ha comenzado una nueva era que va a traernos nueva vida. Al niño, al adolescente y al joven hay que valorizarlos en si mismos, hay que respetarlos,...hay que capacitarlos para que sepan vivir dignamente una vida libre, consagrarse al trabajo y trabarse en estrecha comunidad moral con los hombres de la misma patria y con la comunidad cultural de los hombres: la humanidad.

Cunha ollada menos atenta ao espírito novo convén referirse ao político liberal galego (do núcleo pontevedrés) Eduardo Vincenti y Reguera que en 1910, na súa calidade de presidente da Comisión Permanente do Consello (español) de Instrución Pública, foi delegado do Goberno español e designado pola JAE no terceiro Congreso Internacional de Educación Popular, organizado en Bruxelas pola Liga Belga de Ensino (con Sluys á fronte), ocasión para 0 coñecemento doutras realidades e avances internacionais na educación popular e para confirmar que o ensino debera ser "intuitivo, experimental e integral, dirixirse a todos os sentidos, á sensibilidade e ao corazón", nunha escola, con presenza da modalidade de escolas ao aire libre e de colonias de vacacións, orientada cara ao pacifismo, con presenza de labores froebelianos e outras actividades prácticas, e cun tratamento neutro da educación relixiosa, como signo de tolerancia. ${ }^{67}$

No curso de 1912-1913 dous mestres galegos tiveron ocasión de gozar de pensións para viaxes en grupo. Falamos de Marcelino Pedreira Fernández e de Emilio Sotelo, que viaxaron con percorridos parcialmente diferentes. ${ }^{68}$ Referímonos a Marcelino Pedreira

de Galicia, entre outras contribucións, vid. Anxo S. Porto Ucha, "A formación do profesorado galego: A Xunta para Ampliación de Estudios e as viaxes a Europa”, Adaxe, 5 (1989) 81 e ss.

${ }^{65}$ Eloy Luís André, Educación de la Adolescencia (Madrid: Imprenta de "Alrededor del Mundo", 1916).

${ }^{66} \mathrm{Ibid}$, p. 315. Con imaxes e ideas similares incidía noutro dos seus textos, ao falar da escola "como comunidad libre de trabajo" en El espíritu nuevo en la educación española (Madrid: Sucs. De Ribadeneyra, 1926), 29.

${ }^{67}$ Eduardo Vincenti y Reguera, La Educación Popular. Memoria redactada por... (Madrid: Imprenta de los Hijos de M. G. Hernández, 1911).

${ }^{68}$ Era preciso presentar ante a JAE un proxecto de viaxe de estudos por parte da persoa interesada acerca do seu interese e conveniencia. José Castillejo, como Secretario da JAE, revisaba e valoraba tales proxectos trasladando á Comisión permanente 0 seu informe. A escala de prioridades académicas e a dispoñibilidade de 
noutro momento ${ }^{69}$ Este mestre na cidade da Coruña, entregado á educación de fillos de familias populares e sendo o educador máis significado nas colonias escolares organizadas desde comezo do século ata o 1936, participou nunha viaxe de 30 dias de duración por distintas cidades de Francia, Bélxica, Holanda e Suíza, que podemos seguir grazas ao seu diario de viaxe. ${ }^{70}$

Unha viaxe cun intenso sentido cultural e educativo e cunha coidada combinación onde entraban: as visitas a escolas infantís, primarias, secundarias e Escolas Normais; as realizadas a algúns dos museos, bibliotecas e outros centros culturais das cidades percorridas, e as feitas a espazos da natureza; había tamén tempos de conversa entre os membros do grupo, de intercambio cos docentes e directores das institucións visitadas —baixo a coordinación do profesor Álvarez Santullano — ${ }^{71}$ e tempos de lecer e para facer algunhas compras, dado o caso.

No seu diario deixa constancia de numerosos detalles e de abondosas sorpresas polo contraste coas realidades española e galega. Sorpresas que, en ocasións, proceden de ver inesperadamente escenas e espazos de pobreza, ou comportamentos escolares e docentes que "nada ensinaban" aos docentes españois. Detense con atención na descrición de instalacións escolares.

Nun momento de visita en Zurich, Pedreira sinala: "en una clase hay talleres como los que yo tengo en la escuela que rijo"; "visitamos otra clase en que el profesor y los alumnos trabajan cooperando con mucha naturalidad; otra, en que el profesor conversa y discurre sencillamente con los niños..."; "visitamos el Pestalozzianum y compro dos retratos grandes de la estatua de Pestalozzi en Iverdon, destinado uno de ellos a venerar en mi escuela su memoria"; en el Museo Escolar Suízo en Berna compré un aparato de proyecciones Radioptican, para el que sirven postales, fotografías y dibujos y que usaré en mi escuela"; "Ios escolares usan la letra inglesa"; "al entrar los niños se quitan las botas y ponen zapatillas, así no estropean el piso de linóleo"; "todas las clases tienen alumbrado eléctrico"; "hay gimnasio, cuarto de duchas, salas para guardar las bicicletas; "cerca hay un campo de patinar con muchos niños que así lo hacen"; "la Escuela Normal

recursos anuais levaban a efectuar a concesión, ou non, e en que condicións e períodos de tempo. Logo de cada viaxe así realizado o pensionado debía presentar unha memoria académica ante a JAE, que se convertía, alén do seu valor didáctico e informativo, nun antecedente a considerar no caso dunha posterior petición de bolsa polo mesmo interesado.

${ }^{69}$ Antón Costa, $M^{a} X$. Benítez García: "Marcelino Pedreira: un mestre coruñés baixo a influencia de Pestalozzi e da Escola Nova", Anuario Brigantino, 22 (1999) 221-236.

${ }^{70}$ Marcelino Pedreira Martínez, "Excursión de maestros al extranjero. Año de 1912. Diario de....la Parte". Un documento de 25 cuartillas apaisadas escrito con moi miúda e ben composta letra. Non podemos seguir puntualmente os primeiros momentos de paso por Madrid, desde onde en tren se trasladaron ata París e desde alí a Gante no día 30 de novembro, onde comeza a súa descrición: 0 día 1 de decembro están en Anveres, 0 2 en Bruxas, 03 en Liexa, 04 chegada a Basilea, 05 día de lecer, o 6 e 07 estarán en Zurich, 08 será día de lecer en Lucerna, 09 e 010 realizan visitas en Berna, 0 11, 012 e 013 en Neuchâtel e comarca, os días 14, 15 e 16 fano en Lausanne, 0 17,18 e 19 en Xenebra, e o día 20 e último de actividades chegan a Lyon, desde onde volverían para España aos seus distintos lugares de procedencia.

${ }^{71}$ Participaron nesta viaxe tamén os destacados Ángel Llorca, Natalio Utray e Rodolfo Tomás Samper. 
de Neuchâtel se gobierna por si misma; se vive como en familia; los alumnos eligen cada dos meses un comité de orden, que amonesta si es preciso"; "visitamos el orfelinato de Dombresson, con nueve casas organizadas en familias"; "las aulas de mayores tienen pupitres graduables en altura e inclinación"; "las paredes están decoradas con pinturas de niños jugando"; "a la hora del recreo salen comiendo pan y frutas;" en una clase de Pedagogía en la Escuela Normal de Ginebra el director imparte al grupo una conferencia sobre la enseñanza de la lectura, haciéndonos tomar parte activa en ella"; "asistí a una conferencia sobre educación de anormales impartida por Mmlle. Descoeudres en el Institut J.J. Rousseau ante 19 señoritas y 5 señores, casi todos extranjeros; ella realiza varios ejercicios con niños y explica familiarmente, tomando parte los concurrentes en el desarrollo de las cuestiones: así se enseña y así se aprende"; en el Institut, donde nos habló el director (Claparède) nos dieron una sesión de proyecciones de las escuelas alemanas Lietz, o sea escuelas-granjas con clases al aire libre."

Forma distinta teñen as crónicas da viaxe de Emilio Sotelo Rey, mestre en Bueu. A súa viaxe en grupo, tamén baixo a coordinación de Álvarez Santullano, ${ }^{72}$ transcorreu por distintos lugares de Francia e de Bélxica e diso deixou constancia a través dunha serie de textos de prensa publicados en Faro de Vigo, como antecedente da súa refundición nun libro publicado un anos despois en Ávila, lugar ao que acababa de chegar, despois de iniciar a súa actividade como inspector de educación primaria. ${ }^{73}$ No que agora é do noso interese apreciamos que en París teñen ocasión de observar a realización de exercicios, por parte de alumnos de educación especial, para determinar os tipos de memoria auditiva e visual "para conocer la fuerza de retención y asociación", deténdose noutros exercicios de aplicación dos principios da psicoloxía experimental, que supoñían medicións e o uso da fotografía; no contraste entre países Sotelo observa: "la enseñanza es mucho más práctica en Bélgica sobre Francia"; "en Bélgica cantan mucho: el canto ejerce una acción moral muy grande y despierta en el niño emociones puras y elevados sentimientos"; observa, tamén, a práctica constante de xogos e a presenza de ximnasios nas escolas, onde se cultivan a educación cívica e as actividades artísticas e manuais. Teñen ocasión, igualmente, de apreciar o funcionamento das colonias de vacacións, das cantinas e das escolas froebelianas.

Formou parte desta viaxe a visita á escola de Uccle na contorna de Bruselas, dirixida por Decroly cuns 70 alumnos e alumnas e oito profesores; con clases de 10 a 12 nenos, con tres mesas anchas e horizontais en cada unha delas. "Publican un periódico semanal, El Eco de la Escuela, escrito por los niños y por ellos mismos corregido, que viene a

\footnotetext{
72 Quen será posteriomente o secretario do Padroado de Misións Pedagóxicas.

${ }^{73}$ Emilio Sotelo Rey, Por la Europa pedagógica (con prólogo de Eduardo Vincenti) (Ávila: Tipografía de Sucs. De A. Jiménez, 1913). Logo do seminario de formación organizado en Madrid, a viaxe transcorreu por Bordeaux, París, Bruxas, Ostende e Bruxelas, onde participaron no Congreso de Paidoloxía. Chamoulle a atención constantemente a Sotelo Rey a boa composición e o estado dos edificios escolares visitados (para 500-600 alumnos) sobre o que fai frecuentes descricións, como tamén das aulas; xunto aos varios colexios visitados, situáronse as visitas a Escolas Normais, a da escola de educación especial "na que fai os seus estudos Binet", unha escola de pesca, e unha de horticultura e de agricultura.
} 
ser el reflejo de las observaciones relativas a su vida, a sus progresos educativos y a la enseñanza de la escuela de enorme utilidad" ${ }^{74}$

\title{
Con respecto a Decroly, afirma:
}

viene a ser un revolucionario de la pedagogía; el observa, compara, mide, experimenta; hace ejercicios de expresión y asociación; en una palabra: estudia al niño psicológica y fisiologicamente, luego deduce e investiga y estas deducciones e investigaciones le sirven de norma para trazar en firme el camino del fin que persigue. Vimos prácticamente su obra y además nos explicó cuanto se propone, hablándonos de su labor y contestando con agrado cuantas preguntas le hacíamos. ${ }^{75}$

Alén do estritamente educativo hai no texto de Sotelo apreciacións sobre a construción do coñecemento ou sobre a organización social que nos parece oportuno recoller. Así, logo do paso pola Sorbona escribe:

En el interior de sus paredes es la ciencia, que llama a todos, para admitir las distintas ideas, las distintas opiniones y las más opuestas doctrinas, a fin de someterlas a razonada controversia; de ese choque y discusión constante surge potente el progreso en todos los órdenes de los humanos conocimientos. ${ }^{76}$

\section{Chámalle a atención a organización social de Bélxica:}

\begin{abstract}
Puede decirse que es el país del socialismo y de la cooperación, y asombra el número de sociedades que de todo género existen [...]; con esa cooperación mútua, con ese recíproco auxilio y la acción colectiva alcanzan conquistas asombrosas para su mejoramiento y bienestar, dando al traste con las desigualdades,con los monopolios y con las injusticias, haciendo de ese modo la vida más digna $[$ [...] Quisiéramos que vierais las cooperativas obreras, su labor y el beneficio que reportan a sus asociados. En ellas tienen sus academias, sus escuelas, sus fábricas y almacenes, sus conciertos y sus teatros, sus bibliotecas, sus cafés, sus círculos, sus imprentas y sus periódicos, sus hospitales y servicio médico. ${ }^{77}$
\end{abstract}

Anos máis tarde, en 1921, o inspector corunés Manuel Díaz Rozas desfrutaría dunha pensión en grupo (neste, participaría outro inspector galego, Luciano Seoane Seoane) para a realización dunha viaxe de estudos entre os meses de marzo e abril por terras de Francia, Bélxica e Suíza, que el complementou cunha breve estadía en Inglaterra, que transcorreu entre Londres, Oxford e Cambridge. ${ }^{78}$ Puideron apreciar a utilización da metodoloxía froebeliana xunto á montessoriana, así como "la asociación íntima del objeto, la idea y las representaciones orales y escritas" en varias escolas infantís visitadas en París; aínda que "tenemos ocasión de contemplar en esta ciudad nuevamente el espíritu

\footnotetext{
${ }^{74}$ Ibid., 87.

75 Ibid., 84

${ }^{76}$ Ibid., 39.

77 Ibid., 68-69.

${ }^{78}$ Ocupámonos da biografía e actividades deste inspector en Antón Costa, "La biblioteca que guardaron las gaviotas: memoria bibliográfica de dos inspectores republicanos", Historia de la Educación. Revista interuniversitaria, 17 (1998): 445-451. Díaz Rozas volveu realizar en 1930 outra viaxe pedagóxica por Francia, Bélxica, Suíza e Italia, agora mediante unha pensión individual de catro meses. Temos previsto volver nun futuro próximo e con máis detemento sobre esta figura.
} 
excesivamnte militarista de todos estos grupos, con sus marchas militares; Ios niños suben las escaleras cantando a boca cerrada"; en la École Normale Superieur de Fontenay aux Roses son atendidos por Felix Pecaut, con apelaciones al laicismo; visitan tamén a de Saint Cloud, e aquí suscítase a seguinte reflexión de Díaz Rozas: "No hay derecho a tener a los alumnos tanto tiempo en una clase: no hay atención que resista"; teñen un encontro co Dr. Simon; nos días de estadía en Suíza apreciarán, en particular, os paseos e as colonias de vacacións, así como varias experiencias de self-governement escolar.

Outros e outras profesoras galegas gozaron de pensión ou da condición de pensionado ao longo dos anos vinte e comezos dos trinta, mais aquí só faremos mención de María Barbeito e Cerviño, unha moi destacada educadora coruñesa, directora das escolas graduadas Da Guarda, facticamente convertido en centro de ensaio e reforma baixo a súa dirección, introdutora do montessorianismo na Coruña, e finalmente inspectora-mestre, un cargo que desde 1933 compartiu con outros nove profesores en toda España, como mostra dos seus méritos e do recoñecemento acadado. ${ }^{79}$ En 1935 viaxou en grupo e puido visitar institucións docentes de Francia, Bélxica, Holanda, Alemaña, Suíza e Italia. Ao seu regreso a Galicia tivo ocasión de impartir dez conferencias para o maxisterio da súa zona de inspección, para as que escribiu amplos textos descritivos e valorativos do visto, que conformaron moitos anos despois, en 1975, un libro que titulou Países y Escuelas. ${ }^{80}$

Do seu paso por París e polas escolas maternais quedou a súa valoración: "nada notable de observar"; en Holanda seguiu con atención a organización dunha escola segundo o Plan Dalton norteamericano; observou escolas montessorianas; na Alemaña, cunha fugaz presenza, visitaron unha escola de campo en Hamburgo; en Italia puido tomar contacto con colonias escolares, cunha escola ao aire libre e coa notábel Scuola Rinnovata; ${ }^{81}$ en Suíza visitaron centros en Zurich, Berna e Xenebra e detivéronse sobre todo na Maison des Petits, con alumnado de tres a nove anos de idade, onde recibiron explicacións de boca de Mmlle. Audemars, a prestixiosa directora do centro.

Finalmente, queremos deternos na súa presenza en Bélxica. A María Barbeito sorprendeulle a hostilidade que observou con respecto a Decroly: "indiferencia cuando no hostilidad aplicadas al método Decroly en casi toda Bélgica y países próximos" di na páxina 63, aínda que ela se detén amplamente nas escolas de Uccle e de Montana, onde é recibido o grupo español polas fillas de Decroly, Jadot e Susanne, e di: "participa de las ventajas de ciudad, de campo y de bosque, como cuadra a una escuela nueva que ha de

\footnotetext{
${ }^{79}$ Existe unha magnífica monografía sobre esta profesora escrita por Ana Romero Masiá, María Barbeito. Unha vida ao servizo da escola e dos escolares (1880-1970). (A Coruña: Baía, 2014). Dispón dun prólogo da nosa autoría: "María Barbeito, a nosa grande educadora", pp. 5-14. María Barbeito, unha profesora ben formada, xa en 1913 pronuncia unha conferencia notábel que titulou Niños y Educadores (Ferrol: Imp. de Ferrol, 1913), onde advertía da necesidade dos estudos de antropometría, de fisioloxía e de psicoloxía para unha mellor observación da natureza infantil cara á súa educación.

${ }^{80}$ María Barbeito y Cerviño, Países y Escuelas (La Coruña: Ed. Moret, 1975).

${ }^{81}$ A quen lle dedica vinte páxinas de información e comentarios no libro do que falamos.
} 
ser en concepto de tal higiénica, alegre, de clases poco nutridas y con facilidades por su instalación para una enseñanza, concreta, intuitiva y activa", ${ }^{82}$ sinalando ademais:

\begin{abstract}
La característica de esta escuela después de recorrerla toda es su aspecto de taller y de laboratorio; se ve que el niño elabora en todo caso su propio conocimiento y no se limita como en tantas escuelas de tantas partes a ser un mero receptáculo de lo que se le da hecho; no existen en ninguno de los lugares en que allí se reunen unos cuantos niños la inmovilidad y el silencio, sino un discreto ir y venir para atender cada uno a su trabajo, realizado de un modo personalísimo, con toda libertad de iniciativa y de expresión y que favorece grandemente la espontaneidad y la actividad estimulada con la facultad de poder desenvolverse a gusto. Para la vida y por la vida fue siempre el lema de Decroly y en ese principio se halla basada toda la organización de esta interesantísima escuela. ${ }^{83}$
\end{abstract}

Imaxinamos, despois de ter accedido a textos diversos relacionados coa súa preparación das clases e coas súas intervencións como conferenciante en varios lugares de Galicia, que a acción pedagóxico-didáctica de María Barbeito tiña eses trazos de orientación e que inspiraban o traballo formativo nas escolas Da Guarda.

\title{
Pegadas e mostras na Galicia dos anos vinte
}

Non é doado construír unha "topografía" precisa coas pegadas e mostras escolanovistas na Galicia dos anos vinte. É unha imaxe de algo un pouco disperso ao longo do territorio, urbano ou rural, dependente de accións docentes singulares, se ben contra os últimos anos parece apreciarse algún incipiente movemento de opinión e algún impulso organizativo; por veces, deberemos conformarnos só con pegadas e indicios, debido a que non é doado delimitar en todas as ocasións se unha pegada ou mostra respondía máis a un modelo escolar rexeneracionista —que é sen dúbida o máis frecuente no panorama escolar dos anos vinte e que inclúe expresións do activismo metodolóxicodidáctico -, que á influencia certa da corrente específica ou difusa da "escola nova".

Con estas cautelas iniciamos este trazado. Desta topografía poida que formen parte as actividades de lecer que se propiciaban a través das colonias escolares que durante estes anos se celebraban, con algunha irregularidade, en Vigo, A Coruña, Ferrol, Lugo, Santiago, Pontevedra e Lalín —-con contribucións das administracións municipais-, ou realizadas por impulso privado, como no caso do colexio León XIII de Vilagarcía, ${ }^{84}$ ou as realizadas no concello do Covelo, con apoio procedente de América; colonias que se celebraban nos tempos de verán en localidades diversas da beiramar ou mesmo da montaña. Ao caso é oportuno citar varios nomes de profesores destacados: Marcelino Pedreira para

\footnotetext{
82 Ibid., 70.

${ }^{83}$ Ibid., 78.

${ }^{84} 0$ colexio privado León XIII, fundado con espírito burgués por un docente ourensán, de orientación rexeneracionista e positivista, pasou a ser dirixido desde 1923 polo galeguista Xosé Nuñez Búa, quen paulatinamente foi incorporando neste centro prácticas educativas conformes coa filosofía da "escola nova". En 1936 este director escolar debeu exiliarse á Arxentina, onde seguiu desenvolvendo actividades culturais con orientación política galeguista, e con el tivemos ocasión de soster intercambio de correspondencia.
} 
A Coruña, Juan García Niebla para Ferrol, ${ }^{85}$ Carmen García del Arroyo e Ortíz Novo,${ }^{86}$ que atendían aos colonos enviados desde Madrid polo Museo Pedagóxico, baixo a dirección de Angel do Rego e Edmundo Nóvoa Barros, profesor e masón, 23 anos á fronte das colonias escolares de Vigo.

Se falamos de centros educativos, é preciso salientar o papel de María Barbeito á fronte das Escolas Graduadas da Guarda na cidade da Coruña, como xa referimos. Alí propiciou o funcionamento dunha aula de educación infantil con metodoloxía montessoriana ${ }^{87}$ e preconizaba nas escolas a metodoloxía decrolyana. Conectaba con algunhas das actividades e iniciativas emprendidas desde a sociedade "Reunión Circo de Artesanos" da cidade, que propiciaba actividades como as conferencias e os cursos da Universidade Popular, o grupo esperantista, ${ }^{88}$ ou 0 apoio ao grupo de Exploradores ${ }^{89}$ e ás colonias escolares.

Debemos citar as Escolas de Val Miñor, fundadas pola Sociedade Unión HispanoAmericana Valle Miñor, que impulsou, entre outros, o masón e industrial en América Manuel Lemos, xa estudadas entre nós. Estas escolas incorporaron prácticas pedagóxicas propias do activismo e das Escolas Novas, baixo o maxisterio desde América de Ignacio Ares de Parga e o próximo do mestre e director Eladio Ferreiro.$^{90}$ Con impulsos “americanos", mais non só, convén falar tamén da escola que entre 1924 e 1929 dirixiu 0 mestre Hernán Poza Juncal en Lalín (Pontevedra) no marco da chamada "Escuela Hospital-Asilo", patrocinada pola Sociedad Hijos del Partido de Lalín, en Bos Aires, cuxas

\footnotetext{
${ }^{85}$ Juan García Niebla, 0 máis destacado mestre institucionista en Ferrolterra, respiraba a orientación escolanovista non só na súa escola, senón nas actividades que propiciaba a través do Ateneo de Ferrol e con outros profesores, con frecuentes excursións didácticas e festas da árbore, entre outras iniciativas. Foi autor do folleto, Los hombres de mañana (Imp. y Est. de El Correo Gallego, 1912). Será fusilado en 1936, por socialista e galeguista. Vid. Guillermo Llorca, Juan García Niebla: entre a innovación pedagóxica e o compromiso cidadán (Asociación Cultural de Canido: Muiño do Vento).

${ }^{86}$ Manuel Ortíz Novo, Colonias escolares. La experiencia de Oza de los Ríos (Madrid: Lib. y Casa Edit. Hernando, 1928).

${ }^{87}$ Os datos de que dispomos parecen indicar que foi a introdutora en Galicia, nas Escolas da Guarda, desta innovadora metodoloxía. Recentemente achegamos unha información, aínda imprecisa, que fala da introdución desta metodoloxía na aula de párvulos que formaba parte da Escola Obreira de Ferrol, coa profesora Carmen Castrillón. A este respecto, vid. Lorena Cuevas Bujan \& Cristina Rodríguez Prieto, Escuela Obrera Ferrol. 100 años. Un siglo de porvenir (Ferrol: Navantia, 2016), 94-96. A Escola Obreira foi un centro educativo graduado instalado desde 1916 nun edificio modélico construído nas propias instalacións do Arsenal marítimo-militar de Ferrol, ao servicio dos fillos dos empregados da factoría, baixo a dirección de Andrés López Otero, e desde aquí emprenderanse varias iniciativas de renovación pedagóxica no inicio dos anos trinta.

${ }^{88} 0$ esperantismo foi unha corrente de comunicación que favoreceu os contactos internacionais, como os que se realizaban para a expansión dos ideais da Escola Nova. Na cidade existiu o núcleo esperantista máis sólido en toda Galicia, que gozou do apoio local da casa editora Garcybarra.

${ }^{89}$ Tense sinalado en distintas ocasións a existencia de proximidade entre as actividades e parte da filosofía do movemento dos Exploradores (o movemento de boys scouts) coa filosofía da Escola Nova. 0 movemento dos Exploradores e 0 seu desenvolvemento histórico en Galicia está precisado dun estudo panorámico, pois hai constancia da súa presenza en Galicia desde o comezo dos anos vinte na cidade de Ferrol.

${ }^{90}$ Carlos Méixome, "Noticia dun mestre: Eladio Ferreiro Otero, en Emigración e Educación (1900-1936). $1^{\circ}$ Centenario das Escolas da Unión Hispano-Americana Valle Miñor (1909-2009), ed. Xosé Manuel Malheiro (Nigrán/Gondomar: Instituto de Estudos Miñoranos), 389-412.
} 


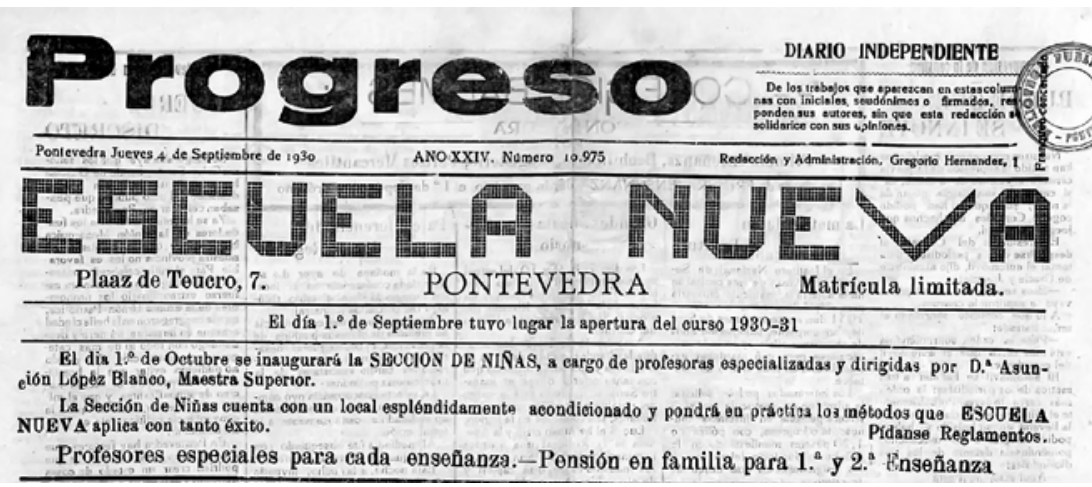

0 profesor Hernán Poza Juncal, logo de anteriores experiencias, parte delas realizadas en Barcelona, promoveu a Escuela Nueva de Pontevedra, que no seu plan de estudos secundarios procedía segundo as indicacións do innovador Instituto-Escuela de Madrid.

instalacións tamén servían no verán para a realización de colonias escolares. 0 profesor incorporaba prácticas escolanovistas, probabelmente "aprendidas" mediante 0 seu contacto con realidades educativas catalás; entre elas promoveu unha sociedade infantil escolar que se propoñía crear unha biblioteca escolar circulante, para favorecer o hábito da lectura; unha biblioteca que en 1927 reunía cerca de 300 libros e folletos, e que era un modo de educación democrática a través da renovación de responsabilidades entre 0 propio alumnado que a coidaba. ${ }^{91}$

Aquí e aló poden verse algúns destacados mestres: é o caso de Xosé Ramón Fernández Oxea ("Ben-Cho-Shey"), ${ }^{92}$ primeiro como profesor en Cariño, nas terras de Ortegal, e logo en Santa Marta de Moreiras (0 Pereiro de Aguiar) entre 1925 e $1935,{ }^{93}$ de onde nos entregou unha extraordinaria monografía etnográfica, impregnada de galeguismo, ${ }^{94}$ que permite percibir a súa comunicación cos nenos e a incorporación que realizou da metodoloxía decroliana nunha contorna aberta á natureza, ${ }^{95}$ pola súa parte, Luís Bello no

\footnotetext{
${ }^{91}$ Vid. Blog "Historia de la tierra de Deza" de Antonio Vidal Neira, 06/01/2016. Recupero 03 de agosto de 2020 en https://historiadeza.wordpress.com/2016/01/06/la-biblioteca-de-la-escuela-hospital-asilo-de-lalin/ Vid. Nota 59 .

${ }^{92}$ Quen tamén gozou dunha viaxe de estudos concedida polas deputacións provinciais de Pontevedra e de Ourense, que lle permitiu coñecer centros educativos de nenos anormais mentais e físicos, institucións para xordomudos e para cegos de Francia e de Bélxica. Vid. Xosé Fernández Fernández, "José Ramón Fernández Ojea e a aplicación da música popular nas escolas", Sarmiento. Revista Galego-Portuguesa de Historia da Educación, 23 (2019), 293-314.

${ }^{93}$ Carmen Benso Calvo e Xosé Fernández. "José Ramón Fernández-0jea, mestre. Memoria do seu paso por dúas escolas galegas," Sarmiento 6 (2006): 277-287.

${ }^{94}$ Antón Costa, "0 ensino no tempo das Irmandades. A 'escola galega' como proxecto", en Arredor das Irmandades da Fala. Pensamento, política e poética en Galicia (1914-1931), coord. Luís Cochón (Vigo: Edicións Xerais e Galicia, 2016), 131-144.

${ }_{95}$ Ben-Cho-Shey, Santa Marta de Moreiras (Sada: Ediciós do Castro,1965).
} 
seu Viaje por las escuelas de Galicia96 fálanos, en particular, do mestre aragonés radicado en Galicia Felipe Carnicer e da súa escola de Vieiro, un xardín escolar no pleno sentido pedagóxico, e debemos anotar que Felipe Carnicer, xunto co mestre José Galera poñen en funcionamento unha biblioteca popular circulante ${ }^{97}$ para 0 servizo dos profesorado das terras da comarca, destacando na súa listaxe bibliográfica os fondos das Publicaciones de Revista de Pedagogía que trasladaban o máis importante monllo de textos de renovación pedagóxica que daquela podían estar a disposición dos lectores en español; podemos igualmente citar 0 dinámico José Otero Espasandín ${ }^{98}$ e a Antonio Magariños Granda, mestres ambos das escolas dos pósitos de pescadores de Ribeira e de Cambados, respectivamente, quen manifestarán a súa adhesión ao espírito da "escola nova". ${ }^{99}$

Sen dúbida, compartía estas perspectivas o malogrado Xoán Vicente Viqueira na súa actividade docente como profesor de Psicoloxía e Lóxica no Instituto da Coruña, pois estudara entre 1911 e 1914 Psicoloxía e Filosofía na Alemaña e viaxara a Francia e a Inglaterra por ser el mesmo un destacado membro da Institución Libre de Enseñanza. ${ }^{100}$ Pola súa banda, o profesor normalista ourensán Vicente Risco, figura estudada noutros lugares, consideraba algunhas orientacións abertas á "escola nova" no seu "Plan pedagóxico pra galeguizazón d’as escolas”, dado á luz en 1920, como analizou o profesor Xosé Fernández.

E o mesmo cabe dicir do profesor Ramón Salgado Toimil, rexeneracionista, que adoptou as súas posicións máis adiantadas nunha conferencia pronunciada na Sociedade Obreira da cidade de Lugo en 1927. ${ }^{101} 0$ espírito do novo en educación podería estar presente, así mesmo, na aprobación dunha partida económica por parte da Delegación de Cultura do Concello de Vigo en 1928 para facer posíbel a viaxe de preto de catro semanas de duración por parte de sete profesores vigueses para o recoñecemento de experiencias escolares en Granada (as "escolas de Ave María"), Cartaxena, Valencia, Madrid e Barcelona, incluído aquí 0 Grupo Escolar Baixeras e a Escola del Bosc, dous emblemas da "nova educación". 102

Un protagonismo singular, por fin, debemos conceder ao profesor vigués Apolinar Torres López, quen desde as páxinas dos xornais Faro de Vigo e El Pueblo Gallego alimentou informativamente entre 1926 e 1930 a corrente de opinión favorábel aos criterios

\footnotetext{
${ }^{96}$ Luis Bello, Viaje por las escuelas de Galicia, (Vigo, Nigratrea, 2010; edición e notas de Antón Costa).

${ }^{97}$ Primer catálogo y reglamento de la Biblioteca Popular Circulante del distrito de Vivero (Patrocinada por la Asociación del Magisterio de este distrito) (La Coruña: Imp. Zincke Hnos., 1929).

${ }^{98}$ Antón Costa. "Xosé Otero Espasandin: un educador galego exiliado en América", Revista Galega de Educación 74 (2019): 82-84.

${ }^{99}$ Uníndose á iniciativa lanzada en 1927 por Apolinar Torres López desde as páxinas de El Pueblo Gallego, a favor de propiciar unha rede de profesores afectos á Escola Nova en Galicia. Antonio Magariños, pola súa parte, publicará o breve texto "La Nueva Era" (El Pueblo Gallego, 23. 11.1927) invitando a promover núcleos de profesores "a modo de secciones locales de la Liga Internacional de la Escuela Nueva".

${ }^{100}$ Dedicámoslle atención de estudo en diversos traballos.

${ }^{101}$ Ramón Salgado Toimil, Puntos cardinales del pensamiento pedagógico contemporáneo. Sociología infantil. Escuela única. Pacifismo (Lugo: Imp. de G. Castro, 1927).

102 Vid. S.a. "Excursión pedagógica de los maestros de Vigo," El Pueblo Gallego (25.09.1928) e Faro de Vigo (11.12. 1928).
} 
e prácticas escolanovistas, facéndoo por medio de páxinas de educación especializadas nestes dous medios, a "Página pedagógica" e "La enseñanza y los maestros", respectivamente. ${ }^{103}$

Escribía Apolinar Torres cunha posición nítida en defensa e difusión da Nova Educación: "Escuela Nueva, Maestro Nuevo, Educación Nueva!!!” —escribía en 1927— cun chamamento aos mestres: "¡Maestros gallegos, agrupad vuestros ideales alrededor de Ios que sustenta la Liga Internacional de la Educación Nueva!!!”, convertendo, así, esta sección de información educativa nun portavoz oficioso do movemento internacional da Escola Nova en Galicia e nun espazo de difusión das súas innovacións e realizacións. Hai que salientar que nas súas numerosas páxinas tiveron unha especial acollida as informacións internacionais ligadas á Liga Internacional das Escolas Novas, filtradas con frecuencia a través da Revista de Pedagogía que dirixía o profesor Lorenzo Luzuriaga. ${ }^{104}$

\section{A topografía ampliada dos anos trinta}

Como sabemos, moi numerosos aspectos da vida social, cultural e política española, e por iso tamén galega, experimentaban daquela procesos de aceleración canto á modernización, á europeización e á expresión das demandas de participación na construción dunha sociedade máis inclusiva e democrática. Finalizado 0 curto período ditatorial vivido desde 1923 abriuse a porta á constitución da II República española 014 de abril de 1931, de orientación liberal-burguesa e socialmente reformadora, que permitiu acoller mellor as demandas populares de contido social, así como as de carácter territorial ao iniciarse a configuración dun Estado con autonomías políticas, entre elas a de Galicia.

Como parte deste proceso hai que situar o crecemento paulatino no número de escolas e de centros de educación secundaria e de formación profesional, co aumento no número de docentes, por mais que tal crecemento - que se viña rexistrando desde os anos vinte- respondese tamén a un proceso de afirmación do Estado como organizador social, con trazos ideolóxicos e identitarios de "españolización" cidadá. Así, os 4526 profesores e profesoras de ensino primario público que en Galicia anotan as estatísticas en 1931 ascenden a un total de 6500 en 1935, o que significaba a incorporación dun profesorado mozo que daquela viña predisposto en moitos casos a compartir os novos ideais da educación.

\footnotetext{
${ }^{103}$ Vid. nota 4.

${ }^{104}$ Así, un aproximado 20\% das notas de información de carácter internacional publicadas en «La Enseñanza y los Maestros", en ocasións cun traslado completo e noutras de modo resumido, foran publicadas previamente na Revista de Pedagogía. 023 de xaneiro de 1929, en que a Sección iniciaba a inclusión —ao longo de seis días- do artigo de A. Ferrière titulado "La educación nueva en la práctica", incorporaba a seguinte nota: "Deseosos de que nuestros lectores estén al día sobre las cuestiones de la Pedagogía moderna, hemos obtenido del ilustre escritor y pedagogo L. Luzuriaga, la autorización necesaria para reproducir los trabajos que creamos más dignos de divulgación de su notable Revista de Pedagogía, la publicación mejor de esta especie que se publica en España" e debemos supoñer con moi fundadas razóns que quen escribía así era Apolinar Torres López. Isto mesmo sucedeu con outras colaboracións; como exemplo, o 12 de maio de 1929 en que se incluía 0 artigo "Pedagogía práctica: el régimen interior de la escuela" de Fernando Sainz, salientábase que 0 artigo estaba tomado do n. 87 da Revista de Pedagogía «con autorización de L. Luzuriaga».
} 
Unha parte dos actores da educación indicados na topografía dos anos vinte proseguirán durante os anos trinta. É o caso de Hernán Poza, quen pon en marcha en 1930 na cidade de Pontevedra o centro "Escuela Nueva", ${ }^{105}$ que se anunciaba sinalando ser 0 único centro en Galicia que dispoñía do mesmo plan de estudos que o Instituto-Escuela creado en Madrid en 1918. E aparecían outros novos: é o caso de Xesús Golmar, familiar de Salgado Toimil, con que logrará unha mellor formación, como se aprecia nos seus coidados textos breves de prensa que irá publicando na revista Vida Escolar de Lugo, que iniciara a súa andadura en 1927;106 na mesma publicación, en 1932, vemos os termos en que se expresa o mestre Quintela Ferreiro, falando da importancia didáctica de conectar o ensino coa natureza e cos intereses do alumnado:

\begin{abstract}
El único libro de valor es la Naturaleza [...]. En los bancos solo estarán los niños cuando escriban; en los libros solo leerán para saberlos interpretar y tomarles aficción. Estas ideas, en la práctica son de muy fácil aplicación. Por la mañana los alumnos saldrán al campo provisos de una libreta de apuntes; allí ante la Naturaleza, el maestro les irá explicando poco a poco lo que ven. Cada día se tomará un objeto como "centro de interés", es decir, partiendo, por ejemplo, de la contemplación de un pino, se darán al niño nociones de cálculo, de moral, de lenguaje y, sobre todo, se procurarán sus sentidos y su potencia discursiva. Ya en la escuela, pondrá en limpio sus notas, practicando la escritura y constribuyendo a que se le graven más las ideas adquiridas ${ }^{107}$.
\end{abstract}

Isto era o que facía na súa escola da parroquia da Rúa (Cervo) o mestre salmantino Julián Pérez Palacios, tal como nos deixou escrito mediante fermosos textos de influencia decroliana, nunha memoria escrita en 1935: "Mi vida en la escuela". ${ }^{108}$ Actividades similares desenvolvíanas outros mestres na provincia de Lugo: Evaristo Cuena desde a súa escola de Tardad na Terra Chá, como apreciou Luís Bello na súa visita; Antonio Pérez López, desde a escola de San Miguel de Reinante, como nos deixou entrever a través dun seu texto publicado na Revista de Pedagogía, que foi impulsor con Juan Arévalo Simón do xornal El Pequeño Escolar, imprentado en Ribadeo para a comunicación interescolar que durante 0 curso de 1935-1936 serviu para conectar un bo número das escolas da Mariña; Luís Diego Cuscoy, que exercía nunha pequena escola rural de Palas de Rei, a quen "localizamos" hai anos a través do exame de números de 1933 da revista L'Éducateur Proletarien, que Freinet dirixía en Francia; e, Gregorio Sanz, tan bo mestre na escola de

\footnotetext{
${ }^{105}$ Situada na praza do Teucro, edificio do Pazo dos Condes e San Román. Un importante centro que se anunciaba indicando ser 0 único en Galicia que «adaptó el plan de estudios del Instituto-Escuela e Madrid».

106 Un conxunto de 28 textos escritos entre 1930 e 1935, que ampliou con outros varios publicados entre 1935 e 1936 en El Pueblo Gallego. No conxunto percibimos o mestre que se deixa imbuír do ideario escolanovista, sen facer unha expresa declaración, nas súas manifestacións sobre os modos didácticos, como cando narra como examinar co alumnado a vida das Iombrigas. Vid. Jesús Golmar, "Contemplando una lombrid!", Vida Escolar, 400 (22.09.1934), 3-4, e Manuel Igrexas, Xesús Golmar. (A Estrada: Edicións Fervenza, 2005).

${ }^{107}$ En Quintela Ferreiro. "Renovación de la escuela rural." El Progreso (18.III. 1932).

108 Julián Pérez Palacios e Julián Jesús Pérez Fernández, Vida y pedagogía de un maestro. Julián Pérez Palacios (1901-1984) (A Coruña: Publicaciones Arenas, 2011). Escolmamos e traducimos ao galego unha parte de tales textos correspondentes coas páxinas 20, 24 e 40 en Antón Costa, Uxía Bolaño Amigo. "Represión política e castigo do profesorado republicano na provincia de Lugo. As consecuencias do 36.". Sarmiento. Revista GalegoPortuguesa de Historia da Educación 21 (2017):101-119.
} 


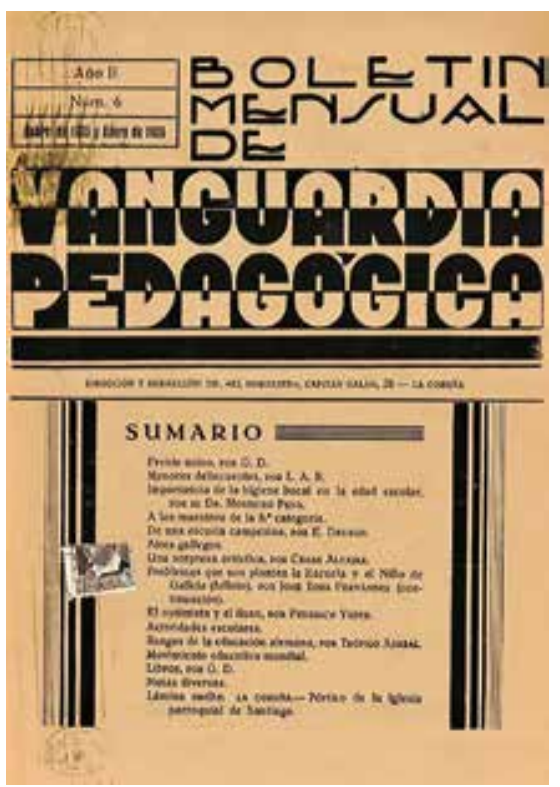

Á altura de 1935 poñíase en marcha o Boletín de Vanguardia Pedagógica, con alcance provincial na Coruña. ĺa unido a iniciativas complementarias tendentes á formación pedagóxica e ao impulso do escolanovismo entre o profesorado.

Benquerencia e logo en Ribade $0^{109}$ que fixo expresar a un dos seus alumnos moitos anos máis tarde:
A escola de don Gregorio atraíanos con forza. Ninguén chegaba con retraso [...] esperando a chegada de don Gregorio que, con estrita puntualidade, sempre con publicacións e libros baixo o brazo [...], cruzaba a alameda camiño da escola [...] Non había xornada en que as nosas mentes non se abriran a un novo coñecemento [...] Asomámonos en clases inesquecíbeis en contacto coa natureza aos nosos vales e montañas. Estudamos as árbores e as flores, acariñando os troncos e as súas follas caprichosas ou admirando o misterio dunha corola aínda chorosa do orballo da mañá. Recorremos as nosas vellas igrexas e monumentos e da súa man entramos na pequena historia da nosa contorna [...] Un día tamén tocamos coas nosas mans o regato mínimo, puro e cristalino, onde comeza a súa andaina galega 0 Pai Miño ${ }^{110}$.

Nas terras de Pontedeume debemos citar a Frutos Fernández Martínez, ligado ás escolas dos pósitos marítimos e que destacou no campo do mutualismo escolar: celebraba frecuentes excursións e visitas didácticas cos nenos e mozos, mantivo por tempo un taller de carpintaría e outro de encadernación, promoveu a creación dun grupo musical

\footnotetext{
${ }^{109}$ Referímonos a eles en varios lugares e, en particular, en Antón Costa, Uxía Bolaño."Represión política e castigo do profesorado republicano na provincia de Lugo. As consecuencias do 36," Sarmiento. Revista GalegoPortuguesa de Historia da Educación 21 (2017):101-119.

${ }^{110}$ Victor Moro, "Limiar" a Gregorio Sanz, Uno de tantos (Sada: Ediciós do Castro, 1990), 6.
} 
de instrumentos de pulso e púa que actuaba a beneficio do mantemento dunha cantina escolar para que todos os nenos tivesen unha comida quente, e un grupo coral de voces infantís; ademais, en 1932 promoveu o xornal escolar Floración, con varios números editados con textos de elaboración infantil e puxo en marcha a Biblioteca Popular Circulante. ${ }^{111}$

Nas terras pontevedresas, xunto ao citado Apolinar Torres, debemos anotar — como fixemos noutras ocasións - os nomes dos inspectores Pedro Caselles ${ }^{112}$ e 0 galeguista Rogelio Pérez González, por favorecer as prácticas da nova educación e a súa difusión a través dos centros de colaboración pedagóxica; ${ }^{113}$ a Antón Alonso Ríos, mestre nas escolas de Tomiño, impulsadas desde a emigración, onde exercía coa formación práctica completada como docente que fora na Arxentina; ${ }^{114}$ a Luís Carragal Peón que a finais de 1932 puxo en marcha en Budiño (0 Porriño) a Cooperativa Rural Escolar anexa á súa escola; ${ }^{115}$ a José Benito González, quen desde A Caniza —como noutras ocasións referín ${ }^{116}$ — promoveu a orientación freinetiana e el mesmo foi participe na "Cooperativa Española de Imprenta en la Escuela" e difusor do xornal escolar Faro infantil; foi, ademais, personaxe activo nas actividades das Misións Pedagóxicas en Galicia ${ }^{117}$ e promotor, xunto ao inspector Muntada Bach, ${ }^{118}$ da celebración de senllas semanas pedagóxicas para 0 profesorado da comarca.

Para 0 caso de Ourense, Xosé M. Cid ten aludido ás actividades pedagóxicas realizadas, entre outros, por Baltasar Vázquez e por Albino Núñez, ${ }^{119}$ membros da dinámica

\footnotetext{
${ }^{111}$ Antón Costa. "0 mestre Frutos Fernández Martínez e o mutualismo escolar. Unha páxina da historia da Educación Social en Galicia." Cátedra. Revista Eumesa de Estudios 26 (2019) 7-17.

112 Vid. Pedro Caselles. "Hacia la nueva escuela," El Pueblo Gallego (13.01.1935).

${ }^{113}$ Debemos salientar un artigo breve publicado por Roxerius en 1925 en defensa da Nova Educación no que indica que recentemente recibirá diversas revistas de La Nouvelle Éducation, para o profesorado, e un número da revista de nenos e para nenos L'oiseau bleu, que lle enviara Roger Cousinet desde Francia. Cousinet fora desde 1922 impulsor da asociación pedagóxica francesa La Nouvelle Educatión, antecedente do Groupe Français de I'Education Nouvelle (GFEN). Vid. «Insinuaciones. La Nouvelle Éducation», Galicia (Vigo), 9.I.1925, p.7.

${ }^{114}$ Vid. Xosé Manuel Malheiro Gutiérrez, As escolas de emigrantes e o pensamento pedagóxico: Ignacio Ares de Parga e Antón Alonso Ríos (Sada-A Coruña: Ediciós do Castro, 2006).

${ }^{115}$ Experiencia que recollemos en distintos momentos nós mesmos e con maior detemento posterior Narciso de Gabriel (Agricultura e escola, 1989) e Anxo Porto Ucha (Historias de vida. 0 maxisterio pontevedrés na II República, Guerra Civil e comezos do Franquismo, 2003).

${ }^{116}$ Antón Costa, "La Pedagogía Freinet en Galicia (1931-1978)". En Págines vives. Quaderns Freinet. Les revistes escolars de la Segona República, ed. Ferrán Zurriaga (Castelló: Cátedra Soler i Godes/Publicación de I'Universitat Jaume I), 57-78.

117 Vid. Eugenio Otero. "As Misións Pedagóxicas na España rural republicana," EDUGA. Revista Galega do Ensino 51(2007): 52-56.

${ }^{118}$ Conxuntamente prepararon un texto sobre a organización de paseos e excursións con interese didáctico, recentemente reeditado con estudo por parte de Anxo Porto Ucha e Raquel Vázquez, La escuela activa y el entorno. Una aproximación a través de los paseos, visitas y excursiones durante la Segunda República, Santiago de Compostela, Andavira, 2017.

${ }^{119}$ Xosé M. Cid, "Albino Nuñez, alumno de Risco na Normal. Un referente do maxisterio ourensán," en Estudos e investigacións na Facultade de Ciencias da Educación de Ourense. Cen anos despois de Risco (1916-2016), ed. Xosé Manuel Cid (Santiago: Andavira, 2016), 42-64.
} 
Asociación de Traballadores do Ensino de Ourense (ATEO). Albino Nuñez presidiu a ATEO en 1932, impulsou La Escuela del Trabajo e en 1935 pasou a dirixir o grupo escolar "Concepción Arenal" na cidade da Coruña, centro que con el tamén pasou a ser "de ensaio e reforma escolar"; na mesma provincia destacaron en escolas da Ribeira Sacra os mestres Alfonso García Rojo e Rosa Pons i Fábregas. ${ }^{120}$ Podemos anotar, ademais, que en 1932 a organización Mocedade galeguista faría un acto na cidade lembrando a Decroly, coa intervención de Vicente Risco, Fernández Oxea e Cesáreo Saco.

\section{"Romper la carcoma en que vegetan los viejos moldes"121}

Varias novas publicacións periódicas, que partían dalgúns sectores máis dinámicos do profesorado, querían contribuír a isto. Este sector do profesorado foi incorporando nas súas lecturas de libros e de prensa a nova orientación. Por iso, podémonos facer eco dunha información públicada no n. ${ }^{0} 141$ de 1933 da Revista de Pedagogía, portavoz da Liga Internacional da Nova Educación en España, que indicaba que a publicación alcanzaba unha tiraxe próxima ás 4000 copias por número: "especial consideración merecen los maestros jóvenes a los que se debe en su mayor parte el aumento de nuestros lectores", e que situaba as provincias galegas en postos notábeis polo número de lectores e subscritores entre as 50 provincias españolas. ${ }^{122}$

Despois da experiencia da sección xornalística "La enseñanza y los maestros" dirixida por Apolinar Torres en El Pueblo Gallego, que Roxelio Pérez González quixo continuar en 1935 sen logralo, debemos sinalar que houbo en Galicia interese en crear medios de información profesional e pedagóxica que auspiciaran a filosofía da "nova educación". Incluso Vida Escolar, desde Lugo, situada no ámbito do rexeneracionismo, abriu as portas e alí, entre outros, expresouse o inspector balear, con breve paso por Lugo nos anos 19291930, Joan Comas, que aproveitou a súa estadía de estudo e de formación no Institut de Pédagogie de Xenebra cabo de Piaget e outros, para enviar breves pero interesantes artigos a esta revista. ${ }^{123}$

La Escuela del Trabajo, con Albino Nuñez á fronte desde 1932 e baixo 0 impulso da ATEO de Ourense, cos seus 26 números mensuais editados ata abril de 1934 favoreceu igualmente esta orientación ${ }^{124}$, como o farían máis decididamente Escuela Vivida de

\footnotetext{
${ }^{120}$ Xosé M. Cid Fernández, Alfonso García Rojo, Mestre republicano da Ribeira Sacra. Relatos autobiográficos (Vigo: Consello Social da Universidade, 2008) e Xosé M. Cid Fernández, Rosa Pons i Fábregas. Unha mestra europea en Parada de Sil (Parada de Sil (Ourense): Concello de Parada de Sil, 2009).

${ }^{121}$ Esta era a expresión que 0 destacado profesor vigués Victor Fraíz utilizou para definir a funcionalidade das novas publicacións do profesorado, ao referirse especificamente á aparición de La Escuela del Trabajo. Victor Fraiz. "Asociación de Trabajadores de la Enseñanza”, El Pueblo Gallego (13.05.1932).

${ }^{122}$ A Coruña e Lugo en $6 .{ }^{\circ}$ e $7 .{ }^{\circ}$ lugar, respectivamente, a de Ourense no posto $12 .^{\circ}$ e a de Pontevedra, no $19 .{ }^{\circ}$ posto.

${ }^{123}$ A figura de Joan Comas, exiliado en México logo de 1936, está hoxe estudada e recoñecida, en particular na área cultural catalá. Colaborou nas edicións que promoveu Lorenzo Luzuriaga. Desde Galicia aludimos á súa biografía académica en Antón Costa, A reforma da educación, op.cit., 31-32 e 189-198.

124 Vid. Xosé M. Cid Fernández, "A revista e os seus redactores" en Educación e ideoloxía en Ourense na $/{ }^{a}$ República (Santiago: Andavira, 2010, segunda edición revisada e ampliada), 87-126. Prestaría a súa cabeceira,
} 
Pontevedra ${ }^{125}$ e o Boletín de Vanguardia Pedagógica, editado desde A Coruña, nos anos 1935-36. ${ }^{126}$

015 de setembro de 1934 nacía na Coruña a "Asociación de Vanguardia Pedagógica", como "institución de renovación escolar" que, entre outras iniciativas, poñerá en marcha na primavera de 1935 o Boletín mensual de Vanguardia Pedagógica. Gustavo Díaz Sánchez, o inspector Manuel Díaz Rozas e o profesor na escola anexa da Escola Normal de Santiago José Toba Fernández foron os máximos impulsores. Entre os diversos artigos e textos dos nove números editados podemos apreciar a atención didáctica concedida ao diario de aula cos nenos, aos campos agrícolas, á lectura como medio de ensino, á imprenta na escola (pedagoxía Freinet) e á "vitalización" escolar a través dos estudos do medio. Percíbese tamén unha consistente preocupación polo movemento pedagóxico internacional, que se reflicte en textos sobre a organización do ensino en Portugal —con mención ao renovador Faria de Vasconcelos-, a formación do profesorado, o Centro de Estudos Decroliano en Bélxica, a educación alemá —con explícito rexeitamento do modelo nacional-socialista—, a escola soviética, a reforma do ensino en Inglaterrra e referencias á educación para a paz.

A Asociación pretendía impulsar un servizo de publicacións pedagóxicas e por iso publica a modo de encartes no Boletín varias separatas de vinte a trinte páxinas, con que logra editar os seguintes textos:

- Nuñez Domínguez, A., "Algunas ideas sobre el mundo del niño" (n. ${ }^{0} 2-3$ )

- Pedreira, M., "Valor social y pedagógico de la Colonia Escolar" (n. $\left.{ }^{0} 4-5\right)$.

- Toba, J., "Problemas que nos plantea la escuela y el niño de Galicia" (n. ${ }^{0}$ 6-7), Neste texto observamos a orientación renovadora da escola ("la escuela gallega deseada, como toda escuela nueva ha de ser vital”), que deberá ser organizada en función dos intereses e da vida dos nenos (p. 18), guiándose pola metodoloxía decroliana dos centros de interese.

\section{Ao cabo, dous escintileos}

A orientación a prol da escola nova e activa debía estar prendendo con estimábel forza sociolóxica no andar dos anos trinta. 0 camiñar case senlleiro da racionalista "Antorcha Galaica del Libre Pensamiento" no comezo do século fora dando paso a un cami-

galeguizada en 1936 (como A Escola do Traballo) para ser emblema e órgano de comunicación da nacente Federación Galega de Traballadores do Ensino, que xa non puido nacer.

${ }^{125}$ Escuela vivida nace en maio de 1935, como órgano de expresión da Casa del Maestro de Pontevedra, editando 59 números (de 8 a 10 pp. en cada caso) ata 017 de xullo de 1936 e faino acompañando, ademais, a Biblioteca Circulante, que en 1935 reunía 500 libros, con atención ás cuestións didácticas e psico-pedagóxicas con horizontes renovadores. Vid. Angel Porto Ucha, Raquel Vázquez Ramil, Organización societaria e depuración do maxisterio. A Casa del Maestro de Pontevedra (1934-1936) (Santiago de Compostela: Fundación Luís Tilve, 2019).

${ }^{126}$ Sobre estes asuntos, Antón Costa, Escolas e mestres. A educación en Galicia entre a Restauración e a II República, (Santiago de Compostela, Xunta de Galicia, 1989). 
ñar colectivo como acabamos de ver e como poden mostrar dous escintileos na fin do percorrido.

Un. Por unha iniciativa do profesor Álvaro das Casas, forxada no curso de 1935-1936 no aínda novo instituto de bacharelato de Noia e baixo a dirección do profesor Carlos Villar, catedrático de Literatura, púxose en marcha no centro a colección editorial "Renascencia" coa participación dos mociños, para a edición en número de cen exemplares por título de pequenos tomos de 30 a 50 páxinas, baixo a administración do propio alumnado: un con 40 alalás, a versión galega de doce sonetos de amor de Camões, dous monólogos en verso, unha selección de cantigas do Cancioneiro da Vaticana, un compendio de xeografía de Galicia, Meus reises (un monólogo para nenos), unha selección de cantigas do rei D. Dinís, e Media ducia de contos, mentres en prensa quedaron unha colección de refráns sobre 0 mar e unha síntese da historia de Galicia. ${ }^{127}$

Dous. Nos días finais de maio de 1936 un importante número de ensinantes galegos, en representación de case 700 asociados e asociadas, reunidos nun congreso en Vigo, constituían a Federación Galega de Traballadores do Ensino con disposición a pular por esta orientación educativa, facendo ao tempo unha afirmación de galeguismo social, que noutros lugares analizamos: a escola como laboratorio de educación e espazo de educación democrática.

Impulsos e accións, entre outras, para a reforma escolar en Galicia e parte da afirmación do proxecto público de educación, cando estaba a nacer a Galicia política autonómica, unindo escola nova, escola activa e escola galega. Un proxecto paralizado pola nacente ditadura, por ter matado os mensaxeiros nuns casos, por causarlles exilio, noutros, e, ao cabo, por ser impulsos e accións que non asentaran aínda con raiceiras abondas entre os sectores sociais democráticos, de modo que os considerasen parte necesaria do proxecto social para relembrar.

Escribimos en 1996 e mantémolo hoxe:

0 legado bibliográfico do inspector Manuel Díaz Rozas [que logo da súa morte silenciosa, permaneceu acochado nunha casa labrega e familiar da Mariña e que descubrimos en 1990], ${ }^{128}$ sintetiza os

\footnotetext{
${ }^{127}$ A finais dos anos setenta do século XX 0 vello estudoso das terras de Muros e Noia Arturo Romaní puido compartir con nós no seu domicilio noiés esta fermosura e mostrarme os títulos editados.

${ }^{128}$ Como demos a coñecer en Antón Costa, A reforma da educación en Galicia (1907-1936), op. cit., 38-49, logo da busca un algo prolongada do rastro biográfico de Manuel Díaz Rozas chegamos en 1990 a unha casa familiar aldeá, onde durmía unha biblioteca de algo máis de 2000 volumes editados, agás excepcións, nas catro primeiras décadas do século XX, entre os que máis de 700 son de pedagoxía e psicoloxía infantil, un terzo destes, ademais, editados en inglés, en francés e en alemán: 0 mellor testemuño que hoxe temos en Galicia da produción editorial europea (e non só) impulsada naquelas décadas polo movemento da Escola Nova e Activa. Unha biblioteca actualmente gardada na Biblioteca de Galicia en Santiago de Compostela. En contraste con esta ruptura e memoria pedagóxica que en Galicia se deu e á que nos referimos en Cataluña permaneceron no tempo do franquismo (catro décadas) a memoria e a presenza viva de Rosa Sensat, de Artur Martorell, de Gali... axudando ao rexurdir, que entre nós foi máis difícil.
} 
infelices avatares do noso desenvolvemento educativo e a ruptura por xeracións da nosa memoria e herdanza pedagóxica, como pedras basais da nosa renovación pedagóxica. ${ }^{129}$

\section{Bibliografía}

Abarrategui, Vicente, “Darío Carames”, Anuario Brigantino, 3 (1951) 132.

Alcántara, Pedro, La educación intelectual y los métodos de enseñanza. Madrid: Gras y Compañía editores, 1886.

Alcántara, Pedro, Educación intuitiva y lecciones de cosas. Madrid: Gras y Compañía, 1881.

Bain, Alexander, La ciencia de la educación. Valencia: Terraz, Aliena y Cía. Editores, 1882.

Baldwin, Mark, Elementos de Psicología. Madrid: La España Moderna, 1893.

Barbeito, María, Países y Escuelas. La Coruña: Ed. Moret, 1975.

Barnés, Domingo, La Paidología. Madrid: Espasa-Calpe, 1936.

Boyd, William, ed., Hacia una Nueva Educación. Relación y síntesis de los debates sobre la nueva psicología y el programa de la quinta conferencia mundial de la Asociación de la Educación Nueva celebrada en Elsinore (Dinamarca) en agosto de 1929. Bilbao: Espasa-Calpe, 1931.

Barreiro, Herminio, Lorenzo Luzuriaga y la renovación educativa en España (1889-1936). Sada: Ediciós do Castro, 1989.

Bello, Luís, Viaje por las escuelas de Galicia. Vigo, Nigratrea, 2010; edición e notas de Antón Costa.

Ben-Che-Shey, Santa Marta de Moreiras. Sada: Ediciós do Castro,1965.

Benso, Carmen \& Fernández, Xose. “José Ramón Fernández-0jea, mestre: memorias do seu paso por dúas escolas galegas." Sarmiento. Anuario Galego de Historia da Educación 10 (2006): 271-287.

Blais, Marie-Claude et alii. Conditions de I'Éducation. París: Fayard/Pluriel, 2010.

Caselles, Pedro, "Hacia la nueva escuela”, El Pueblo Gallego, 13.01.1935.

${ }^{129}$ Antón Costa, A reforma da educación..., op.cit., 49. 
Cid Fernández, Xosé Manuel, Alfonso García Rojo, Mestre republicano da Ribeira Sacra. Relatos autobiográficos. Vigo: Consello Social da Universidade, 2008.

Cid, Xosé Manuel. Rosa Pons i Fábregas. Unha mestra europea en Parada de Sil. Parada de Sil (Ourense): Concello de Parada de Sil, 2009.

Cid, Xosé Manuel. Educación e ideoloxía en Ourense durante a Ila República. Organización e acción socioeducativa do maxisterio primario. Santiago: Andavira, 2. ${ }^{a}$. Edic. rev. e ampl., 2010.

Cid, Xosé Manuel. “Albino Nuñez, alumno de Risco na Normal. Un referente do maxisterio ourensán". En Estudos e investigacións na Facultade de Ciencias da Educación de Ourense. Cen anos despois de Risco (1916-2016), coord. por Xosé Manuel Cid, 42-64. Santiago: Andavira, 2016.

Chycky, Marie-Christine et Jacques George, “L'éducation toujours nouvelle”, Les Cahiers Pédagogiques, 395 (2001), 2-4.

Claparède, Edouard, Psychologie de l'enfant et Pédagogie experimentale. Genève: Librairie Kundig, 1916, 6. ${ }^{\text {a }}$ edición.

Costa, Antón. Escolas e mestres. A educación en Galicia da Restauración á II República. Santiago de Compostela: Servicio de Publicacións da Xunta de Galicia, 1989.

Costa, Antón. A reforma da educación (1906-1936). X.V. Viqueira e a historia da psicopedagoxía en Galicia. Sada (A Coruña): Do Castro, 1996.

Costa Antón. "La biblioteca que guardaron las gaviotas: memoria bibliográfica de dos inspectores republicanos." Historia de la Educación. Revista interuniversitaria 17 (1998): 445-451.

Costa, Antón. "A presencia da Institución Libre de Enseñanza en Betanzos." Anuario Brigantino 11 (1988): 61-68.

Costa, Antón, M. ${ }^{a}$ X. Benítez. "Marcelino Pedreira: un mestre corunés baixo a influencia de Pestalozzi e da Escola Nova." Anuario Brigantino 22 (1999): 221-236.

Costa, Antón. "Darwinismo/evolucionismo e Pedagoxía”, en 0 Darwinismo e Galicia, ed. por Francisco Díaz-Fierros, 187-206. Santiago de Compostela: Servizo de Publicacións da Universidade de Santiago, 2009.

Costa, Antón, “La Pedagogía Freinet en Galicia (1931-1978)”. En Págines vives. Quaderns Freinet. Les revistes escolars de la Segona República, ed. por Ferrán Zurriaga, 57-78. Castelló: Cátedra Soler i Godes/Publicación de I'Universitat Jaume I, 2012. 
Costa, Antón. "María Barbeito e Cerviño, a nosa grande educadora". En María Barbeito. Unha vida ao servizo da escola e dos escolares (1880-1970), ed. por Ana Romero, 5-14. A Coruña: Baía Edicións, 2014.

Costa, Antón. "0 ensino no tempo das Irmandades. A 'escola galega' como proxecto", en Arredor das Irmandades da Fala. Pensamento, política e poética en Galicia (19141931) ed. por Luís Cochón, 131-144. Vigo: Edicións Xerais de Galicia, 2016.

Costa, Antón, Bolaño Uxía. "Represión política e castigo do profesorado republicano na provincia de Lugo. As consecuencias do 36." Sarmiento. Revista Galego-Portuguesa de Historia da Educación 21 (2017):101-119.

Costa, Antón. "As varias paisaxes da escola en Galicia." En Castelao Maxistral, ed. por Miguel Anxo Seixas Seoane, 64-103. Santiago de Compostela: Xunta de Galicia, 2018.

Costa, Antón, Uxía Bolaño. "Galería de profesorado galego en América nos séculos XIX-XX (Arxentina, Uruguai, Cuba).” Anuario Brigantino 40 (2017): 219-246.

Costa, Antón. "0 mestre Frutos Fernández Martínez e o mutualismo escolar. Unha páxina da historia da Educación Social en Galicia." Cátedra. Revista Eumesa de Estudios 26 (2019): 7-17.

Costa, Antón. "Xosé Otero Espasandin: un educador galego exiliado en América." Revista Galega de Educación 74 (2019): 82-84.

Costa, Antón. "Modernidade pedagóxica e reivindicación da Escola Nova na prensa da cidade de Vigo (1926-1929): a figura do profesor Apolinar Torres López (18941936)." Glaucopis. Instituto de Estudios Vigueses 24 (2019): 253-292 .

Cuevas Bujan, Lorena \&Cristina Rodríguez Prieto, Escuela Obrera Ferrol. 100 años. Un siglo de porvenir. Ferrol: Navantia, 2016.

Ferrer C. Maura, Salvador, Una institución docente española. La Escuela de Estudios Superiores del Magisterio (1909-1932). Madrid: Cedesa, 1973.

Fernández Cortina, Manuel, El gorro frigio. Liberalismo, Democracia, República. Madrid: Biblioteca Nueva, 2000.

Fernández, Xosé. "José Ramón Fernández 0jea e a aplicación da música popular nas escolas." Sarmiento. Revista Galego-Portuguesa de Historia da Educación 23 (2019): 293-314.

Ferriere, Adolphe, La escuela activa. Madrid: Beltrán, 1926. 
Ferrière, Adolphe, La ley biogenética y la escuela activa. Madrid: Publicaciones de la Revista de Pedagogía, 1928.

Gabriel, Narciso de. Agricultura e escola. Contra a rutina e o éxodo rural. Santiago: Universidade de Santiago, 1989.

García, Enrique, Froebel y su sistema de educación. Pontevedra: Imprenta de la Vda. e Hijos de Madrigal, 1887.

Hameline, Daniel, et alii, L'école active.Textes fondateurs. París: PUF, 1995.

García Niebla, Juan, Los hombres de mañana. Imp. y Est. de El Correo Gallego, 1912.

Golmar, Jesús. “Contemplando una lombrid!”. Vida Escolar 400 (1934):17.

Gutiérrez, María Luísa. "Aproximación a un espacio educativo: la Residencia de estudiantes normalistas de la Escuela Normal de Maestros de Barcelona (1923-1934)." Revista de Educación 323 (2000)

Igrexas, Manuel. Xesús Golmar. A Estrada: Edicións Fervenza, 2005.

Luís André, Eloy. Educación de la Adolescencia. Madrid: Imprenta de "Alrededor del Mundo", 1916.

Luís André, Eloy, El espíritu nuevo en la educación española. Madrid: Sucs. De Ribadeneyra, 1926.

Luzuriaga, Lorenzo. Concepto y desarrollo de la nueva educación. Madrid: Publicaciones de la Revista de Pedagogía, 1932, 2. a edición renovada.

Luzuriaga, Lorenzo. “Les trente points caractéristiques de l'École publique renovée.” Pour I'Ére Nouvelle, 40 (1928): 146-153..

Malheiro, Xosé Manuel, As escolas de emigrantes e o pensamento pedagóxico: Ignacio Ares de Parga e Antón Alonso Ríos. Sada: Ediciós do Castro, 2006.

Malheiro, Xosé Manuel. "A influencia do contexto educativo arxentino na Unión HispanoAmericana Valle Miñor a través do pedagogo Ignacio Ares de Parga. En Emigración e Educación (1900-1936). $I^{\circ}$ Centenario das Escolas da Unión Hispano-Americana Valle Miñor (1909-2009), coord. por Xosé M. Malheiro, 297-319. Nigrán/ Gondomar: Instituto de Estudos Miñoranos, 2011.

Marín Eced, Teresa. Innovadores de la educación en España (Becarios de la JAE). Cuenca: Ediciones de la Universidad de Castilla-La Mancha, 1991. 
Méixome, Carlos. "Noticia dun mestre: Eladio Ferreiro Otero. En Emigración e Educación (1900-1936). I I Centenario das Escolas da Unión Hispano-Americana Valle Miñor (1909-2009), coord. por Xosé M. Malheiro, 389-412. Nigrán/Gondomar: Instituto de Estudos Miñoranos, 2011.

Molero Pintado, Antonio, Del Pozo Andrés (eds.), Escuela de Estudios Superiores del Magisterio (1909-1932). Alcalá de Henares: Servicio de Publicaciones de la Universidad, 1989.

Morando, Dante, Pedagogía: Historia crítica del problema educativo. Barcelona: Luís Miracle, 1953.

Montes, Soledad. "Aproximación bibliográfica y profesional a la figura de Gerardo Rodríguez García, impulsor del asociacionismo del magisterio." Sarmiento. Anuario Galego de Historia da Educación 3 (1999):183-204.

Ortíz Novo, Manuel, Colonias escolares. La experiencia de Oza de los Ríos .Madrid: Lib. y Casa Edit. Hernando, 1928.

Otawi, Dominique, De Darwin a Piaget. Para uma história da psicologia da criança. Lisboa: Instituto Piaget, 2004.

Otero, Eugenio. “As Misións Pedagóxicas na España rural republicana.” EDUGA. Revista Galega do Ensino 51(2007): 52-56.

Pereira, Carlos. "A Familia Poza. Un exemplo de republicanismo e librepensamento en Pontevedra." Anuario Brigantino 27 (2004): 265-312.

Peña, Vicente. "El pulso de la vida. Narrativas y representaciones de la cotidianeidad en la primera prensa escolar infantil de Galicia (1905-1913)." En La prensa de Ios escolares y estudiantes. Su contribución al patrimonio histórico-educativo, coord.. por José María Hernández, 143-164. Salamanca: Ediciones Universidad de Salamanca, 2015.

Pérez Palacios e Julián Jesús Pérez Fernández, Vida y pedagogía de un maestro. Julián Pérez Palacios (1901-1984). A Coruña: Publicaciones Arenas, 2011.

Porto Ucha, Angel S., La Institución Libre de Enseñanza en Galicia. Sada: Ediciós do Castro, 1986.

Porto, Anxo. "A formación do profesorado galego: A Xunta para Ampliación de Estudios e as viaxes a Europa." Adaxe 5 (1989): 81 e ss. 
Porto, Anxo. Historias de vida. 0 maxisterio pontevedrés na Il República, Guerra Civil e comezos do Franquismo. Ponteareas: Alén Miño, 2003.

Porto, Angel, Vázquez, Raquel, La escuela activa y el entorno. Una aproximación a través de los paseos, visitas y excursiones durante la Ila República. Santiago de Compostela: Andavira, 2017.

Porto Ucha, A. S., Vázquez, Raquel, A “Casa del Maestro" de Pontevedra. Organización societaria e depuración do Maxisterio (1934-1936). Santiago de Compostela: Fundación Luís Tilve, 2019.

Quintela Ferreiro. “Renovación de la escuela rural.” El Progreso (18.III. 1932).

Rodríguez, Gerardo. “Las Escuelas Nuevas.” La Escuela Moderna 487 (1932): 146.

Rodríguez, Gerardo,"Pedagogía engañosa." La Escuela Moderna 150 (1903).

Rodríguez, Gerardo. "De la pedagogía filosófica a la pedagogía científica." La Escuela Moderna" 1-2 (1920) 6-7.

Romero, Ana. María Barbeito. Unha vida ao servizo da escola e dos escolares (18801970). A Coruña: Baía, 2014.

Salgado Toimil, Ramón, Puntos cardinales del pensamiento pedagógico contemporáneo. Sociología infantil. Escuela única. Pacifismo. Lugo: Imp. de G. Castro, 1927.

Sánchez Sarto, Luís, Diccionario de Pedagogía. Barcelona: Labor, 1936.

Sanz, Gregorio, Uno de tantos. Sada: Ediciós do Castro, 1990.

Soler, Joan. "La escuela activa de Adolfo Ferrière en la pedagogía española e iberoamericana". En Influencias suízas en la educación española e iberoamericana, ed. por José María Hernández Díaz, 69-82. Salamanca: Universidad, 2016.

Sotelo Rey, Eduardo, Por la Europa pedagógica. Ávila: Tipografía de Sucs. De A. Jiménez, 1913.

Vázquez Cores, Francisco. “Digna actitud.” La Unión Gallega 61 (15.10.1882): 160-161.

Vincenti y Reguera, Eduardo, La Educación Popular. Memoria redactada por... Madrid: Imprenta de los Hijos de M. G. Hernández, 1911. 